\title{
A New Hybrid Projection Algorithm for System of Equilibrium Problems and Variational Inequality Problems and Two Finite Families of Quasi- $\phi$-Nonexpansive Mappings
}

\author{
Pongrus Phuangphoo ${ }^{1,2}$ and Poom Kumam ${ }^{1}$ \\ ${ }^{1}$ Department of Mathematics, Faculty of Science, King Mongkut's University of Technology Thonburi (KMUTT), Bang Mod, \\ Thung Kru, Bangkok 10140, Thailand \\ ${ }^{2}$ Department of Mathematics, Faculty of Education, Bansomdejchaopraya Rajabhat University (BSRU), Thonburi, \\ Bangkok 10600, Thailand
}

Correspondence should be addressed to Poom Kumam; poom.kum@kmutt.ac.th

Received 28 July 2012; Revised 24 September 2012; Accepted 28 September 2012

Academic Editor: Yongfu Su

Copyright (C) 2013 P. Phuangphoo and P. Kumam. This is an open access article distributed under the Creative Commons Attribution License, which permits unrestricted use, distribution, and reproduction in any medium, provided the original work is properly cited.

We introduce a modified Mann's iterative procedure by using the hybrid projection method for solving the common solution of the system of equilibrium problems for a finite family of bifunctions satisfying certain condition, the common solution of fixed point problems for two finite families of quasi- $\phi$-nonexpansive mappings, and the common solution of variational inequality problems for a finite family of continuous monotone mappings in a uniformly smooth and strictly convex real Banach space. Then, we prove a strong convergence theorem of the iterative procedure generated by some mild conditions. Our result presented in this paper improves and generalizes some well-known results in the literature.

\section{Introduction}

Throughout this paper, we denote by $\mathbb{R}$ and $\mathbb{N}$ the set of all real numbers and the set of all positive numbers, respectively. We also assume that $E$ is a real Banach space and $E^{*}$ is the dual space of $E$. Let $C$ be a nonempty, closed and convex subset of a real Banach space $E$ with the dual $E^{*}$. We recall the following definitions.

A mapping $A: C \rightarrow C$ is said to be nonexpansive if

$$
\|A x-A y\| \leq\|x-y\|, \quad \forall x, y \in C .
$$

A mapping $A: C \rightarrow E^{*}$ is said to be monotone if for each $x, y \in C$, such that

$$
\langle x-y, A x-A y\rangle \geq 0 .
$$

A mapping $A: C \rightarrow E^{*}$ is said to be $\delta$-strongly monotone if there exists a constant $\delta>0$ such that

$$
\langle x-y, A x-A y\rangle \geq \delta\|x-y\|^{2}, \quad \forall x, y \in C .
$$

A mapping $A: C \rightarrow E^{*}$ is said to be $\delta$-inverse strongly monotone if there exists a constant $\delta>0$ such that

$$
\langle x-y, A x-A y\rangle \geq \delta\|A x-A y\|^{2}, \quad \forall x, y \in C .
$$

If $A$ is $\delta$-inverse strongly monotone, then it is Lipschitz continuous with constant $1 / \delta$, that is, for all $x, y \in C, \| A x-$ $A y\|\leq(1 / \delta)\| x-y \|$.

Clearly, the class of monotone mappings include the class of $\delta$-inverse strongly monotone mappings.

Let $A: C \rightarrow E^{*}$ be a monotone mapping. The variational inequality problem is to find a point $z \in C$ such that

$$
\langle y-z, A z\rangle \geq 0, \quad \forall y \in C .
$$

The set of the solution of the variational inequality problem is denoted by $\mathrm{VI}(C, A)$.

Let $C$ be a nonempty, closed and convex subset of a smooth, strictly convex and reflexive Banach space $E$, let $T$ : $C \rightarrow C$ be a mapping, and $F(T)$ be the set of fixed points of $T$. 
A point $x \in C$ is said to be a fixed point of $T$ if $T x=x$. The set of the solution of the fixed point of $T$ is denoted by $F(T):=\{x \in C: T x=x\}$.

A point $p \in C$ is said to be an asymptotic fixed point of $T$ if there exists a sequence $\left\{x_{n}\right\} \subset C$ such that $x_{n} \rightarrow p$ and $\left\|x_{n}-T x_{n}\right\| \rightarrow 0$. We denoted the set of all asymptotic fixed points of $T$ by $\widehat{F}(T)$.

A point $p \in C$ is said to be a strong asymptotic fixed point of $T$ if there exists a sequence $\left\{x_{n}\right\} \subset C$ such that $x_{n} \rightarrow p$ and $\left\|x_{n}-T x_{n}\right\| \rightarrow 0$. We denoted the set of all strong asymptotic fixed points of $T$ by $\widetilde{F}(T)$.

Let $F: C \times C \rightarrow \mathbb{R}$ be a bifunction. The equilibrium problem is to find a point $z \in C$ such that

$$
F(z, y) \geq 0, \quad \forall y \in C .
$$

The set of the solution of equilibrium problem is denoted by $\operatorname{EP}(F)$. Numerous problems in sciences, mathematics, optimizations, and economics reduced to find a solution of equilibrium problems. The equilibrium problems include variational inequality problems and fixed point problem, and optimization problems as special cases (see, e.g., [13]). Recently, many authors have considered the problem for finding the common solution of fixed point problems, the common solution of equilibrium problems, and the common solution of variational inequality problems.

In 1953, Mann [4] introduced the iterative sequence $\left\{x_{n}\right\}_{n \in \mathbb{N}}$ which is defined by

$$
x_{n+1}=\alpha_{n} x_{n}+\left(1-\alpha_{n}\right) T x_{n}
$$

where the initial element $x_{0} \in C$ is arbitrary, $T$ is a nonexpansive mapping, and $\left\{\alpha_{n}\right\}$ is the sequence in $[0,1]$ such that $\lim _{n \rightarrow \infty} \alpha_{n}=0$ and $\sum_{n=1}^{\infty} \alpha_{n}=\infty$. The sequence of (7) is generally referred to as the Mann iteration.

In 2009, Takahashi and Zembayashi [5] introduced the following iterative scheme by the shrinking projection method, and they proved that $\left\{x_{n}\right\}_{n \in \mathbb{N}}$ converges strongly to $q=\Pi_{\mathrm{EP}(F) \cap F(S)}$, under appropriate conditions.

Theorem TZ. Let $E$ be a uniformly smooth and uniformly convex real Banach space, and let $C$ be a nonempty, closed and convex subset of $E$. Let $F$ be a bifunction from $C \times C$ to $\mathbb{R}$ satisfying (A1)-(A4) and let $T$ be a relatively nonexpansive mapping from $C$ into itself such that $F(S) \cap \operatorname{EP}(F) \neq \emptyset$. Let $\left\{x_{n}\right\}$ be a sequence generated by

$$
\begin{gathered}
x_{0} \in C_{0}=C \text { chosen arbitrary, } \\
y_{n}=J^{-1}\left(\alpha_{n} J x_{n}+\left(1-\alpha_{n}\right) J T x_{n}\right), \\
u_{n} \in C \text { such that } F\left(u_{n}, y\right)+\frac{1}{r_{n}}\left\langle y-u_{n}, J u_{n}-J y_{n}\right\rangle \geq 0, \\
C_{n+1}=\left\{z \in C_{n}: \phi\left(z, u_{n}\right) \leq \phi\left(z, x_{n}\right)\right\}, \quad \forall y \in C, \\
x_{n+1}=\Pi_{C_{n+1}}\left(x_{0}\right), \quad \forall n \geq 0,
\end{gathered}
$$

for every $n \in \mathbb{N} \cup\{0\}$, where $J$ is the duality mapping on $E$, the sequence $\alpha_{n} \subset[0,1]$ satisfies $\liminf _{n \rightarrow \infty} \alpha_{n}\left(1-\alpha_{n}\right)>0$, and $\left\{r_{n}\right\}_{n \in \mathbb{N}} \subset(0, \infty)$ satisfies $\liminf _{n \rightarrow \infty} r_{n}>0$. Then, the sequence $\left\{x_{n}\right\}$ converges strongly to $\Pi_{F(S) \cap \mathrm{EP}(f)} x_{0}$, where $\Pi_{F(S) \cap \mathrm{EP}(F)} x_{0}$ is the generalized projection of $E$ onto $F(S) \cap$ $\mathrm{EP}(F)$.

In 2009, Qin et al. [6] extended the iterative process (8) from a single relatively nonexpansive mapping to two relatively quasi-nonexpansive mappings. In 2011, Zegeye and Shahzad [7] introduced an iterative process for finding an element in the common fixed point set of finite family of closed relatively quasi-nonexpansive mappings, common solutions of finite family of equilibrium problems, and common solutions of the finite family of variational inequality problems for monotone mappings in Banach spaces.

Theorem ZS. Let $C$ be a nonempty, closed and convex subset of a uniformly smooth and strictly convex real Banach space $E$ with the dual $E^{*}$. Let $f_{k}: C \times C \rightarrow \mathbb{R}, k=1,2,3, \ldots, L$, be a finite family of bifunctions. Let $S_{j}: C \rightarrow C, j=1,2,3, \ldots, D$ be a finite family relatively quasi-nonexpansive mappings and $A_{i}: C \rightarrow E^{*}, i=1,2,3, \ldots, N$ be a finite family of continuous monotone mappings.

For $x \in E$, they define mappings $F_{r_{n}}, T_{r_{n}}: E \rightarrow C$ by

$$
\begin{aligned}
F_{r_{n}} x:= & \left\{z \in C:\left\langle y-z, A_{n} z\right\rangle\right. \\
& \left.\quad+\frac{1}{r_{n}}\langle y-z, J z-J x\rangle \geq 0, \forall y \in C\right\}, \\
T_{r_{n}} x:= & \left\{z \in C: f_{n}(z, y)\right. \\
& \left.+\frac{1}{r_{n}}\langle y-z, J z-J x\rangle \geq 0, \forall y \in C\right\},
\end{aligned}
$$

where $S_{n} \equiv S_{n}(\bmod D), A_{n} \equiv A_{n}(\bmod N), f_{n}(\cdot, \cdot) \equiv f_{n}(\bmod$ $L)(\cdot, \cdot)$, and $\left\{r_{n}\right\}_{n \in \mathbb{N}} \subset\left[c_{1}, \infty\right)$ for some $c_{1}>0$. Assume that $\mathscr{F}:=\left(\bigcap_{j=1}^{D} F\left(S_{j}\right)\right) \bigcap\left(\bigcap_{i=1}^{N} \operatorname{VI}\left(C, A_{i}\right)\right) \bigcap\left(\bigcap_{k=1}^{L} \operatorname{EP}\left(f_{k}\right)\right) \neq \emptyset$. Let $\left\{x_{n}\right\}$ be a sequence generated by

$$
\begin{gathered}
x_{0} \in C_{0}=C \text { chosen arbitrary, } \\
z_{n}=F_{r_{n}} x_{n}, \\
u_{n}=T_{r_{n}} x_{n}, \\
y_{n}=J^{-1}\left(\alpha_{0} J x_{n}+\alpha_{1} J z_{n}+\alpha_{2} J S_{n} u_{n}\right), \\
C_{n+1}=\left\{z \in C_{n}: \phi\left(z, y_{n}\right) \leq \phi\left(z, x_{n}\right)\right\}, \\
x_{n+1}=\prod_{C_{n+1}}\left(x_{0}\right), \quad \forall n \geq 0,
\end{gathered}
$$

where the real numbers $\alpha_{0}, \alpha_{1}, \alpha_{2} \in(0,1)$ such that $\alpha_{0}+\alpha_{1}+$ $\alpha_{2}=1$. Then, $\left\{x_{n}\right\}_{n \in \mathbb{N}}$ converges strongly to an element of $\mathscr{F}$.

In this paper, motivated and inspired by the previously mentioned above results, we introduce a new iterative procedure for solving the common solution of system of equilibrium problems for a finite family of bifunctions satisfying certain conditions and the common solution of fixed point 
problems for two countable families of quasi- $\phi$-nonexpansive mappings and the common solution of variational inequality problems for a finite family of monotone mappings in a uniformly smooth and strictly convex real Banach space. Then, we prove a strong convergence theorem of the iterative procedure generated by the conditions. The results obtained in this paper extend and improve several recent results in this area.

\section{Preliminaries}

A Banach space $E$ is said to be strictly convex if $\|x+y\| / 2<$ 1 for all $x, y \in E$ with $\|x\|=\|y\|=1$ and $x \neq y$. It is said to be uniformly convex if $\lim _{n \rightarrow \infty}\left\|x_{n}-y_{n}\right\|=0$ for any two sequences $\left\{x_{n}\right\}$ and $\left\{y_{n}\right\}$ in $E$ such that $\left\|x_{n}\right\| \leq 1,\left\|y_{n}\right\| \leq 1$ and

$$
\lim _{n \rightarrow \infty}\left\|\frac{x_{n}+y_{n}}{2}\right\|=1 \text {. }
$$

Let $U_{E}=\{x \in E:\|x\|=1\}$ be the unit sphere of $E$. Then the Banach space $E$ is said to be smooth if

$$
\lim _{t \rightarrow 0} \frac{\|x+t y\|-\|x\|}{t}
$$

exists for each $x, y \in U_{E}$. It is said to be uniformly smooth if the limit (12) is attained uniformly for all $x, y \in U_{E}$.

Let $E$ be a Banach space. Then a function $\rho_{E}: \mathbb{R}^{+} \rightarrow \mathbb{R}^{+}$ is said to be the modulus of smoothness of $E$ if

$$
\rho_{E}(t)=\sup \left\{\frac{\|x+y\|+\|x-y\|}{2}-1:\|x\|=1,\|y\|=t\right\} \text {. }
$$

The space $E$ is said to be smooth if $\rho_{E}(t)>0, \forall t>0$ and is said to be uniformly smooth if and only if $\lim _{t \rightarrow 0^{+}} \rho_{E}(t) / t=0$.

The modulus of convexity of $E$ is the function $\delta_{E}:[0,2] \rightarrow$ $[0,1]$ defined by

$$
\delta_{E}(\epsilon)=\inf \left\{1-\left\|\frac{x+y}{2}\right\|:\|x\| \leq 1,\|y\| \leq 1 ;\|x-y\| \geq \epsilon\right\} .
$$

A Banach space $E$ is said to be uniformly convex if and only if $\delta_{E}(\epsilon)>0$ for all $\epsilon \in(0,2]$.

We recall the following definitions.

Definition 1. Let $C$ be a nonempty set.

(1) A mapping T:C $\rightarrow C$ is said to be closed if for each $\left\{x_{n}\right\} \subset C, x_{n} \rightarrow x$ and $T x_{n} \rightarrow y$ imply $T x=y$.

(2) A mapping $T: C \rightarrow C$ is said to be quasi- $\phi$-nonexpansive (relatively quasi-nonexpansive) if $F(T) \neq \emptyset$, and

$$
\phi(p, T x) \leq \phi(p, x), \quad \forall x \in C, p \in F(T) .
$$

(3) A mapping $T: C \rightarrow C$ is said to be relatively nonexpansive $[8,9]$ if $F(T) \neq \emptyset, F(T)=\widehat{F}(T)$ and

$$
\phi(p, T x) \leq \phi(p, x), \quad \forall x \in C, p \in F(T) .
$$

(4) A mapping $T: C \rightarrow C$ is said to be weak relatively nonexpansive [10] if $F(T) \neq \emptyset, F(T)=\widetilde{F}(T)$ and

$$
\phi(p, T x) \leq \phi(p, x), \quad \forall x \in C, p \in F(T) .
$$

Remark 2. We here the following basic properties.

(1) Each relatively nonexpansive mapping is closed.

(2) The class of quasi- $\phi$-nonexpansive mappings contains properly the class of weak relatively nonexpansive mappings as a subclass, but the converse may be not true.

(3) The class of weak relatively nonexpansive mappings contains properly the class of relatively nonexpansive mappings as a subclass, but the converse may be not true.

(4) The class of quasi- $\phi$-nonexpansive mappings contains properly the class of relatively nonexpansive mappings as a subclass, but the converse may be not true.

(5) If $E$ is a real uniformly smooth Banach space, then $J$ is uniformly continuous on each bounded subset of $E$.

(6) If $E$ is a strictly convex reflexive Banach space, then $J^{-1}$ is hemicontinuous, that is, $J^{-1}$ is norm-to-weak ${ }^{*}$ continuous.

(7) If $E$ is a smooth and strictly convex reflexive Banach space, then $J$ is single-valued, one-to-one, and onto.

(8) A Banach space $E$ is uniformly smooth if and only if $E^{*}$ is uniformly convex.

(9) Each uniformly convex Banach space $E$ has the KadecKlee property, that is, for any sequence $\left\{x_{n}\right\} \subset E$, if $\left\{x_{n}\right\} \rightarrow x \in E$ and $\left\|x_{n}\right\| \rightarrow\|x\|$, then $x_{n} \rightarrow x$.

(10) A Banach space $E$ is strictly convex if and only if $J$ is strictly monotone, that is,

$$
\begin{array}{r}
\left\langle x-y, x^{*}-y^{*}\right\rangle>0, \quad \text { whenever } x, y \in E, \\
x \neq y, x^{*} \in J x, y^{*} \in J y .
\end{array}
$$

(11) Both uniformly smooth Banach spaces and uniformly convex Banach spaces are reflexive.

(12) $E^{*}$ is uniformly convex, then $J$ is uniformly norm-tonorm continuous on each bounded subset of $E$.

Let $E$ be a real Banach space and $\left\{x_{n}\right\}$ be a sequence in $E$. We denote by $x_{n} \rightarrow x$ and $x_{n} \rightarrow x$ the strong convergence and weak convergence of $\left\{x_{n}\right\}$, respectively. The normalized duality mapping $J$ from $E$ to $2^{E^{*}}$ is defined by

$$
J x=\left\{f^{*} \in E^{*}:\left\langle x, f^{*}\right\rangle=\|x\|^{2}=\left\|f^{*}\right\|^{2}\right\}, \quad \forall x \in E,
$$

where $\langle\cdot, \cdot\rangle$ denotes the duality pairing. It is well known that if $E$ is smooth, then $J$ is single-valued and demicontinuous, and if $E$ is uniformly smooth, then $J$ is uniformly continuous on bounded subset of $E$. Moreover, if $E$ is reflexive and strictly convex Banach space with a strictly convex dual, then $J^{-1}$ is single-valued, one-to-one, surjective, and it is the duality 
mapping from $E^{*}$ to $E$ and so $J J^{-1}=I_{E^{*}}$ and $J^{-1} J=I_{E}$ (see $[11,12])$. We note that in a Hilbert space $H$, the mapping $J$ is the identity operator.

Now, let $E$ be a smooth and strictly convex reflexive Banach space. As Alber (see [13]) and Kamimura and Takahashi (see [14]) did, the Lyapunov functional $\phi: E \times E \rightarrow \mathbb{R}^{+}$ is defined by

$$
\phi(x, y)=\|x\|^{2}-2\langle x, J y\rangle+\|y\|^{2}, \quad \forall x, y \in E .
$$

It follows from Kohsaka and Takahashi (see [15]) that $\phi(x, y)=0$ if and only if $x=y$ and that

$$
(\|x\|-\|y\|)^{2} \leq \phi(x, y) \leq(\|x\|+\|y\|)^{2} .
$$

Further suppose that $C$ is nonempty, closed and convex subset of $E$. The generalized, projection (Alber see [13]) $\Pi_{C}$ : $E \rightarrow C$ is defined by for each $x \in E$,

$$
\Pi_{C}(x)=\arg \min _{y \in C} \phi(x, y) .
$$

Remark 3. If $E$ is a real Hilbert space $H$, then $\phi(x, y)=\| x-$ $y \|^{2}$ and $\Pi_{C}=P_{C}$ (the metric projection of $H$ onto $C$ ).

Lemma 4 (Alber [13]). Let $C$ be a nonempty, closed and convex subset of a smooth and strictly convex reflexive Banach space $E$, and let $x \in E$. Then

$$
\begin{aligned}
& \phi\left(x, \Pi_{C}(y)\right)+\phi\left(\Pi_{C}(y), y\right) \\
& \quad \leq \phi(x, y), \quad \forall x \in C, \forall y \in E .
\end{aligned}
$$

Lemma 5 (Kamimura and Takahashi [14]). Let $C$ be a nonempty, closed and convex subset of a smooth and strictly convex reflexive Banach space $E$, and let $x \in E$ and $\widehat{p} \in C$. Then,

$$
\widehat{p}=\Pi_{C}(x) \Longleftrightarrow\langle\widehat{p}-y, J x-J \widehat{p}\rangle \geq 0, \quad \forall y \in C .
$$

Lemma 6 (Qin et al. [6] and Kohsaka and Takahashi [16]). Let $E$ be a smooth, strictly convex and reflexive Banach space, and $A \subset E \times E^{*}$ is a continuous monotone mapping with $A^{-1}(0) \neq \phi$. Then, it is proved in [16] that the resolvent $J_{r}:=$ $(J+r A)^{-1} J$, for $r>0$ is quasi- $\phi$-nonexpansive. Moreover, if $T: E \rightarrow E$ is quasi- $\phi$-nonexpansive, then using the definition of $\phi$ one can show that $F(T)$ is closed and convex (see [6]).

Lemma 7 (Kamimura and Takahashi [14]). Let $E$ be a uniformly convex and smooth real Banach space and let $\left\{x_{n}\right\}$ and $\left\{y_{n}\right\}$ be two sequences of $E$. If $\phi\left(x_{n}, y_{n}\right) \rightarrow 0$ and either $\left\{x_{n}\right\}$ or $\left\{y_{n}\right\}$ is bounded, then $\left\|x_{n}-y_{n}\right\| \rightarrow 0$.

Lemma 8. Let $E$ be a uniformly smooth and strictly convex Banach space with the Kadec-Klee property, let $\left\{x_{n}\right\}$ and $\left\{y_{n}\right\}$ be two sequences of $E$, and $p \in E$. If $x_{n} \rightarrow p$ and $\phi\left(x_{n}, y_{n}\right) \rightarrow 0$, then $y_{n} \rightarrow p$.
For solving the equilibrium problem, let us assume that the bifunction $F: C \times C \rightarrow \mathbb{R}$ satisfies the following conditions:

(A1) $F(x, x)=0$, for all $x \in C$;

(A2) $F$ is monotone, that is, $F(x, y)+F(y, x) \leq 0, \forall x, y \in$ $C$;

(A3) $\lim _{t \rightarrow 0} F(t z+(1-t) x, y) \leq F(x, y), \forall x, y, z \in C$;

(A4) for any $x \in C, y \mapsto F(x, y)$ is convex and lower semicontinuous.

Lemma 9 (Blum and Oettli [1]). Let $C$ be a nonempty, closed and convex subset of a smooth and strictly convex reflexive Banach space $E$ and let $F: C \times C \rightarrow \mathbb{R}$ be a bifunction satisfying the following conditions (A1)-(A4). Let $r>0$ be any given number and $x \in E$ be any point. Then, there exists a point $z \in C$ such that

$$
F(z, y)+\frac{1}{r}\langle y-z, J z-J x\rangle \geq 0, \quad \forall y \in C .
$$

Lemma 10 (Takahashi and Zembayashi [5]). Let $C$ be $a$ nonempty, closed and convex subset of a uniformly smooth and strictly convex real Banach space $E$, and $F: C \times C \rightarrow \mathbb{R}$ be a bifunction satisfying the following conditions (A1)-(A4). Let $r>0$ be any given number and $x \in E$ be any point defined a mapping $T_{r}: E \rightarrow C$ as follows. Then, there exists a point $z \in C$ such that

$$
\begin{aligned}
T_{r}(x)= & \{z \in C: F(z, y) \\
& \left.+\frac{1}{r}\langle y-z, J z-J x\rangle \geq 0, \forall y \in C\right\} .
\end{aligned}
$$

Then, the following conclusions hold:

(1) $T_{r}$ is single-valued;

(2) $T_{r}$ is a firmly nonexpansive type mapping, that is,

$$
\begin{aligned}
\left\langle T_{r} x\right. & \left.-T_{r} y, J T_{r} x-J T_{r} y\right\rangle \\
& \leq\left\langle T_{r} x-T_{r} y, J x-J y\right\rangle, \quad \forall x, y \in E ;
\end{aligned}
$$

(3) $F\left(T_{r}\right)=\mathrm{EP}(F)$;

(4) $\mathrm{EP}(F)$ is a closed and convex subset of $C$;

(5) $\phi\left(p, T_{r} x\right)+\phi\left(T_{r} x, x\right) \leq \phi(p, x), \forall p \in F\left(T_{r}\right)$.

Lemma 11 (Zegeye and Shahzad [7]). Let $C$ be a nonempty, closed and convex subset of a uniformly smooth and strictly convex real Banach space $E$, and $A: C \times E^{*} \rightarrow \mathbb{R}$ be a continuous monotone mapping. Let $r>0$ be any given number and $x \in E$ be any point defined a mapping $K_{r}: E \rightarrow C$ as follows:

$$
\begin{aligned}
K_{r}(x)= & \{z \in C:\langle y-z, A z\rangle \\
& \left.+\frac{1}{r}\langle y-z, J z-J x\rangle \geq 0, \forall y \in C\right\} .
\end{aligned}
$$


Then, the following conclusions hold:

(1) $K_{r}$ is single valued;

(2) $F\left(K_{r}\right)$ is a firmly nonexpansive type mapping, that is,

$$
\begin{aligned}
\left\langle K_{r} x\right. & \left.-K_{r} y, J K_{r} x-J K_{r} y\right\rangle \\
& \leq\left\langle K_{r} x-K_{r} y, J x-J y\right\rangle, \quad \forall x, y \in E ;
\end{aligned}
$$

(3) $F\left(K_{r}\right)=\operatorname{VI}(C, A)$;

(4) $\operatorname{VI}(C, A)$ is a closed and convex subset of $C$;

(5) $\phi\left(p, K_{r} x\right)+\phi\left(K_{r} x, x\right) \leq \phi(p, x), \forall p \in F\left(K_{r}\right)$.

Lemma 12 (Xu [17]). Let $E$ be a uniformly convex Banach space, let $B_{r}(0)$ be a closed ball of $E$, where $r>0$. Then, there exists a continuous, strictly increasing, and convex function $g:[0, \infty) \rightarrow[0, \infty)$ with $g(0)=0$ such that

$$
\|\alpha x+\beta y\|^{2} \leq \alpha\|x\|^{2}+\beta\|y\|^{2}-\alpha \beta g(\|x-y\|),
$$

for all $x, y \in B_{r}(0)$ and all $\alpha, \beta \in[0,1]$ with $\alpha+\beta=1$.

\section{Main Results}

In this section, we prove a strong convergence theorem which solves the problem for finding a common solution of the system of equilibrium problems and variational inequality problems and fixed point problems in Banach spaces.

Theorem 13. Let $C$ be a nonempty, closed and convex subset of a uniformly smooth and strictly convex real Banach space $E$ which has the Kadec-Klee property. Suppose that

(1) $\left\{F_{k}\right\}_{k=1}^{M}: C \times C \rightarrow \mathbb{R}$ is a finite family of bifunctions satisfying conditions (A1)-(A4), where $k=1,2,3, \ldots$, $M$;

(2) $\left\{T_{i}\right\}_{i=1}^{D}$ and $\left\{S_{i}\right\}_{i=1}^{D}$ are two finite families of quasi- $\phi$ nonexpansive mappings from $C$ into $E$, where $i=$ $1,2,3, \ldots, D$;

(3) $\left\{A_{n}\right\}_{n=1}^{N}: C \rightarrow E^{*}$ is a finite family of continuous monotone mappings, where $n=1,2,3, \ldots, N$;

(4) For $x \in E$, one defines the mappings $K_{r_{n}}, T_{r_{n}}: E \rightarrow C$ by

$$
\begin{aligned}
K_{r_{n}}(x):= & \left\{z \in C:\left\langle y-z, A_{n} z\right\rangle\right. \\
& \left.\quad+\frac{1}{r_{n}}\langle y-z, J z-J x\rangle \geq 0, \forall y \in C\right\}, \\
T_{r_{n}}(x):= & \left\{z \in C: F_{n}(z, y)\right. \\
& \left.+\frac{1}{r_{n}}\langle y-z, J z-J x\rangle \geq 0, \forall y \in C\right\} .
\end{aligned}
$$

Assume that $\Omega:=\left(\bigcap_{i=1}^{D} F\left(T_{i}\right)\right) \bigcap\left(\bigcap_{i=1}^{D} F\left(S_{i}\right)\right) \bigcap\left(\bigcap_{k=1}^{M}\right.$ $\left.\operatorname{SEP}\left(F_{k}\right)\right) \bigcap\left(\bigcap_{n=1}^{N} \operatorname{VI}\left(C, A_{n}\right)\right)$ is a nonempty and bounded in $C$. Let $\left\{x_{n}\right\}$ be a sequence generated by

$$
\begin{gathered}
x_{0} \in C_{0}=C, \text { chosen arbitrary, } \\
z_{n}=K_{r_{n}} x_{n}, \\
u_{n}=T_{r_{n}} x_{n}, \\
y_{n}=J^{-1}\left(\alpha J x_{n}+\beta J T_{n} z_{n}+\gamma J S_{n} u_{n}\right), \\
C_{n+1}=\left\{z \in C_{n}: \phi\left(z, y_{n}\right) \leq \phi\left(z, x_{n}\right)\right\}, \\
x_{n+1}=\prod_{C_{n+1}}\left(x_{0}\right), \quad \forall n \geq 0,
\end{gathered}
$$

where $A_{n} \equiv A_{n}(\bmod N), F_{n} \equiv F_{n}(\bmod M), T_{n} \equiv T_{n}(\bmod$ $D), S_{n} \equiv S_{n}(\bmod D),\left\{r_{n}\right\} \subset[a, \infty)$ for some $a>0$ and $n \epsilon$ $\mathbb{N}$ and $\alpha, \beta, \gamma$ are real numbers in $(0,1)$ such that $\alpha+\beta+\gamma=1$. Then, the sequence $\left\{x_{n}\right\}_{n=0}^{\infty}$ converges strongly to $\widehat{p}=\Pi_{\Omega}\left(x_{0}\right)$.

Proof. We will complete this proof by seven steps below.

Step 1. We will show that $C_{n}$ is closed and convex for each $n \geq 0$.

From the definition of $C_{n}$, it is obvious that $C_{n}$ is closed. Moreover, since

$$
\begin{aligned}
& \phi\left(z, y_{n}\right) \leq \phi\left(z, x_{n}\right) \text { is equivalent to } \\
& 2\left\langle z, J x_{n}-J y_{n}\right\rangle-\left\|x_{n}\right\|^{2}+\left\|y_{n}\right\|^{2} \leq 0 .
\end{aligned}
$$

It follows that $C_{n}$ is convex for each $n \geq 0$. Therefore, $C_{n}$ is closed and convex for each $n \geq 0$.

Step 2. We will show that $\Omega \subset C_{n}$ for each $n \geq 0$.

From the assumption, we see that $F \subset C_{0}=C$. Suppose that $F \subset C_{k}$ for some $k \geq 1$. Now, for $p \in \Omega$, Since $S_{k}$ and $T_{k}$ are quasi- $\phi$-nonexpansive and by Lemmas 10 and 11, we compute

$$
\begin{aligned}
\phi\left(p, y_{k}\right)= & \phi\left(p, J^{-1}\left(\alpha J x_{k}+\beta J T_{k} z_{k}+\gamma J S_{k} u_{k}\right)\right) \\
= & \|p\|^{2}-2\left\langle p, \alpha J x_{k}+\beta J T_{k} z_{k}+\gamma J S_{k} u_{k}\right\rangle \\
& +\left\|\alpha J x_{k}+\beta J T_{k} z_{k}+\gamma J S_{k} u_{k}\right\|^{2} \\
\leq & \|p\|^{2}-2 \alpha\left\langle p, J x_{k}\right\rangle-2 \beta\left\langle p, J T_{k} z_{k}\right\rangle \\
& -2 \gamma\left\langle p, J S_{k} u_{k}\right\rangle+\alpha\left\|J x_{k}\right\|^{2}+\beta\left\|J T_{k} z_{k}\right\|^{2} \\
& +\gamma\left\|J S_{k} u_{k}\right\|^{2} \\
= & \alpha \phi\left(p, x_{k}\right)+\beta \phi\left(p, T_{k} z_{k}\right)+\gamma \phi\left(p, S_{k} u_{k}\right) \\
\leq & \alpha \phi\left(p, x_{k}\right)+\beta \phi\left(p, z_{k}\right)+\gamma \phi\left(p, u_{k}\right) \\
= & \alpha \phi\left(p, x_{k}\right)+\beta \phi\left(p, K_{r_{k}} x_{k}\right)+\gamma \phi\left(p, T_{r_{k}} x_{k}\right) \\
\leq & \alpha \phi\left(p, x_{k}\right)+\beta \phi\left(p, x_{k}\right)+\gamma \phi\left(p, x_{k}\right) \\
= & (\alpha+\beta+\gamma) \phi\left(p, x_{k}\right) \\
= & \phi\left(p, x_{k}\right) .
\end{aligned}
$$


Therefore, $p \in C_{k+1}$. By the induction, this implies that $\Omega \subset$ $C_{n}$ for each $n \geq 0$.

Hence, the sequence $\left\{x_{n}\right\}$ is well defined.

Step 3. We will show that the sequence $\left\{x_{n}\right\}$ is bounded.

Let $G:=\bigcap_{n=0}^{\infty} C_{n}$. From $\Omega \subset C_{n}$ for each $n \geq 0$ and $\left\{x_{n}\right\}$ is well defined. From the assumption of $G$, we see that $G$ is closed and convex subset of $C$.

Let $\widehat{p}=\Pi_{G}\left(x_{0}\right)$, where $\widehat{p}$ is the unique element that satisfies inf $\operatorname{in}_{x \in G} \phi\left(x, x_{0}\right)=\phi\left(\hat{p}, x_{0}\right)$. Now, we will show that $\left\|x_{n}-\widehat{p}\right\| \rightarrow 0$ as $n \rightarrow \infty$.

From the assumption of $C_{n}$, we know that $C \supset C_{1} \supset C_{2} \supset$ $C_{3} \supset \cdots$ and since $x_{n}=\Pi_{C_{n}}\left(x_{0}\right)$ and $x_{n+1}=\Pi_{C_{n+1}}\left(x_{0}\right) \in$ $C_{n+1} \subset C_{n}$. Using Lemma 4, we get

$$
\phi\left(x_{n}, x_{0}\right) \leq \phi\left(x_{n+1}, x_{0}\right) \leq \cdots \leq \phi\left(\widehat{p}, x_{0}\right),
$$

for all $\widehat{p} \in \Omega \subset C_{n}$, where $n \geq 1$. Then, the sequence $\left\{\phi\left(x_{n}, x_{0}\right)\right\}$ is bounded. Hence, the sequence $\left\{x_{n}\right\}$ is also bounded.

Step 4. We will show that there exists $\widehat{p} \in C$ such that $x_{n} \rightarrow \widehat{p}$, as $n \rightarrow \infty$. have

Since $x_{n}=\Pi_{C_{n}}\left(x_{0}\right)$ and $x_{n+1}=\Pi_{C_{n+1}} x_{0} \in C_{n+1} \subset C_{n}$, we

$$
\phi\left(x_{n}, x_{0}\right) \leq \phi\left(x_{n+1}, x_{0}\right), \quad \forall n \geq 0 .
$$

Therefore, the sequence $\left\{\phi\left(x_{n}, x_{0}\right)\right\}$ is nondecreasing. Hence $\lim _{n \rightarrow \infty} \phi\left(x_{n}, x_{0}\right)$ exists. By the definition of $C_{n}$, one has that $C_{m} \subset C_{n}$ and $x_{m}=\Pi_{C_{m}} x_{0} \in C_{n}$ for any positive integer $m \geq n$.

It follows that

$$
\begin{aligned}
\phi\left(x_{m}, x_{n}\right) & =\phi\left(x_{m}, \Pi_{C_{n}} x_{0}\right) \\
& \leq \phi\left(x_{m}, x_{0}\right)-\phi\left(\Pi_{C_{n}} x_{0}, x_{0}\right) \\
& =\phi\left(x_{m}, x_{0}\right)-\phi\left(x_{n}, x_{0}\right) .
\end{aligned}
$$

Since $\lim _{n \rightarrow \infty} \phi\left(x_{n}, x_{0}\right)$ exists, by taking $m, n \rightarrow \infty$ in (37), we have $\phi\left(x_{m}, x_{n}\right) \rightarrow 0$.

From Lemma 7, it follows that $\left\|x_{m}-x_{n}\right\| \rightarrow 0$ as $m, n \rightarrow$ $\infty$. Thus $\left\{x_{n}\right\}$ is a Cauchy sequence.

Without a loss of generalization, we can assume that $x_{n} \rightarrow$ $p_{0} \in E$. Since $\left\{x_{n}\right\}$ is bounded and $E$ is reflexive. Since $G:=$ $\bigcap_{n=0}^{\infty} C_{n}$ is closed and convex, it follows that $p_{0} \in G, \forall n \geq$ 0 . Moreover, by using the weak lower semicontinuous of the norm on $E$ and (35), we obtain

$$
\begin{aligned}
\phi\left(\hat{p}, x_{0}\right) & \leq \phi\left(p_{0}, x_{0}\right) \\
& \leq \liminf _{n \rightarrow \infty} \phi\left(x_{n}, x_{0}\right) \\
& \leq \limsup _{n \rightarrow \infty} \phi\left(x_{n}, x_{0}\right) \\
& \leq \inf _{x \in G} \phi\left(x, x_{0}\right) \\
& =\phi\left(\widehat{p}, x_{0}\right) .
\end{aligned}
$$

This implies that

$$
\lim _{n \rightarrow \infty} \phi\left(x_{n}, x_{0}\right)=\phi\left(\hat{p}, x_{0}\right)=\phi\left(p_{0}, x_{0}\right)=\inf _{x \in G} \phi\left(x, x_{0}\right) \text {. }
$$

By using Lemma 5 , we have $\left\langle\widehat{p}-p_{0}, J \widehat{p}-J p_{0}\right\rangle=0$ and hence, $\widehat{p}=p_{0}$. By the definition of $\phi$, we get

$$
\begin{aligned}
\liminf _{n \rightarrow \infty} \phi\left(x_{n}, x_{0}\right) & =\liminf _{n \rightarrow \infty}\left(\left\|x_{n}\right\|^{2}-2\left\langle x_{n}, J x_{0}\right\rangle+\left\|x_{0}\right\|^{2}\right) \\
& \geq\|\hat{p}\|^{2}-2\left\langle\widehat{p}, J x_{0}\right\rangle+\left\|x_{0}\right\|^{2} \\
& =\phi\left(\widehat{p}, x_{0}\right) .
\end{aligned}
$$

Therefore, $\left\|x_{n}\right\| \rightarrow\|\widehat{p}\|$. Since $x_{n} \rightarrow \widehat{p}$, by the Kadec-Klee property of $E$, we obtain

$$
\lim _{n \rightarrow \infty} x_{n}=\widehat{p}
$$

From $J$ is uniformly continuous, we also have

$$
\lim _{n \rightarrow \infty} J x_{n}=J \widehat{p}
$$

Step 5. We will show that $y_{n} \rightarrow \widehat{p}, z_{n} \rightarrow \widehat{p}$ and $u_{n} \rightarrow \widehat{p}$ as $n \rightarrow \infty$.

Since $x_{n+1} \in C_{n+1}$, we have $\phi\left(x_{n+1}, y_{n}\right) \leq \phi\left(x_{n+1}, x_{n}\right) \rightarrow$ 0 , as $n \rightarrow \infty$. Thus, from (21), we obtain

$$
\left\|y_{n}\right\| \longrightarrow\|\hat{p}\|, \quad \text { as } n \longrightarrow \infty,
$$

and so

$$
\left\|J y_{n}\right\| \longrightarrow\|J \hat{p}\|, \quad \text { as } n \longrightarrow \infty \text {. }
$$

This implies that $\left\{J y_{n}\right\}$ is bounded. Note that reflexivity of $E$ implies reflexivity of $E^{*}$. Thus, we assume that $J y_{n} \rightarrow y \in E^{*}$. Furthermore, the reflexivity of $E$ implies there exists $x \in E$ such that $y=J x$. Then, it follows that

$$
\begin{aligned}
\phi\left(x_{n+1}, y_{n}\right) & =\left\|x_{n+1}\right\|^{2}-2\left\langle x_{n+1}, J y_{n}\right\rangle+\left\|y_{n}\right\|^{2} \\
& =\left\|x_{n+1}\right\|^{2}-2\left\langle x_{n+1}, J y_{n}\right\rangle+\left\|J y_{n}\right\|^{2} .
\end{aligned}
$$

Taking the $\liminf _{n \rightarrow \infty}$ on both sides of (45) and using weak lower semicontinuous of norm to get that

$$
\begin{aligned}
0 & \geq\|\hat{p}\|^{2}-2\langle\hat{p}, y\rangle+\|y\|^{2} \\
& =\|\hat{p}\|^{2}-2\langle\hat{p}, J x\rangle+\|J x\|^{2} \\
& =\|\hat{p}\|^{2}-2\langle\hat{p}, J x\rangle+\|x\|^{2} \\
& =\phi(\widehat{p}, x) .
\end{aligned}
$$

Thus $\widehat{p}=x$, and so $y=J x=J \widehat{p}$. It follows that $J y_{n} \rightarrow J \widehat{p}$. Now, from (44) and the Kadec-Klee property of $E^{*}$, we obtain

$$
J y_{n} \longrightarrow J \widehat{p}, \quad \text { as } n \longrightarrow \infty \text {. }
$$


Thus the demicontinuity of $J^{-1}$ implies that $y_{n} \rightarrow \widehat{p}$. Now, from (43) and the fact that $E$ has the Kadec-Klee property, we obtain

$$
\lim _{n \rightarrow \infty} y_{n}=\widehat{p}
$$

In the fact that $x_{n} \rightarrow \widehat{p}$ and $y_{n} \rightarrow \widehat{p}$ as $n \rightarrow \infty$, we get

$$
\lim _{n \rightarrow \infty} \phi\left(p, z_{n}\right)=\phi(p, \widehat{p}) \text {. }
$$

Since $z_{n}=K_{r_{n}} x_{n}$, it follows from Lemma 11 that

$$
\begin{aligned}
\phi\left(z_{n}, x_{n}\right) & =\phi\left(K_{r_{n}} x_{n}, x_{n}\right) \\
& \leq \phi\left(p, x_{n}\right)-\phi\left(p, K_{r_{n}} x_{n}\right) \\
& \leq \phi\left(p, x_{n}\right)-\phi\left(p, z_{n}\right) \longrightarrow 0, \quad \text { as } n \longrightarrow \infty .
\end{aligned}
$$

From (21), we obtain

$$
\left\|z_{n}\right\| \longrightarrow\|\hat{p}\|
$$

and so $\left\{z_{n}\right\}$ is bounded. Since $E$ is reflexive, we assume that $z_{n} \rightarrow z \in E$. It follows that

$$
\phi\left(z_{n}, x_{n}\right)=\left\|z_{n}\right\|^{2}-2\left\langle z_{n}, J x_{n}\right\rangle+\left\|J x_{n}\right\|^{2} .
$$

Taking the $\liminf \operatorname{in}_{n \rightarrow \infty}$ on both sides of (52) and using the continuity of $J$, we get that

$$
\begin{aligned}
0 & \geq\|z\|^{2}-2\langle z, J \widehat{p}\rangle+\|J \widehat{p}\|^{2} \\
& =\phi(z, \widehat{p}) .
\end{aligned}
$$

This implies that $\widehat{p}=z$ and hence $z_{n} \rightarrow \widehat{p}$.

Now, from (51) and the Kadec-Klee property of $E$, we obtain

$$
\lim _{n \rightarrow \infty} z_{n}=\widehat{p}
$$

In the fact that $x_{n} \rightarrow \widehat{p}, y_{n} \rightarrow \widehat{p}$ and $z_{n} \rightarrow \widehat{p}$ as $n \rightarrow \infty$, we get

$$
\lim _{n \rightarrow \infty} \phi\left(p, u_{n}\right)=\phi(p, \widehat{p})
$$

Since $u_{n}=T_{r_{n}} x_{n}$, it follows from Lemma 10 that

$$
\begin{aligned}
\phi\left(u_{n}, x_{n}\right) & =\phi\left(T_{r_{n}} x_{n}, x_{n}\right) \\
& \leq \phi\left(p, x_{n}\right)-\phi\left(p, T_{r_{n}} x_{n}\right) \\
& \leq \phi\left(p, x_{n}\right)-\phi\left(p, u_{n}\right) \longrightarrow 0, \quad \text { as } n \longrightarrow \infty .
\end{aligned}
$$

From (21), we obtain

$$
\left\|u_{n}\right\| \longrightarrow\|\hat{p}\|
$$

and so $\left\{u_{n}\right\}$ is bounded. Since $E$ is reflexive, we assume that $u_{n} \rightarrow u \in E$. It follows that

$$
\phi\left(u_{n}, x_{n}\right)=\left\|u_{n}\right\|^{2}-2\left\langle u_{n}, J x_{n}\right\rangle+\left\|J x_{n}\right\|^{2}
$$

Taking the $\liminf _{n \rightarrow \infty}$ on both sides of (58) and using the continuity of $J$, we get that

$$
\begin{aligned}
0 & \geq\|u\|^{2}-2\langle u, J \widehat{p}\rangle+\|J \widehat{p}\|^{2} \\
& =\phi(u, \widehat{p}) .
\end{aligned}
$$

This implies that $\widehat{p}=u$ and hence $u_{n} \rightarrow \widehat{p}$.

Now, from (57) and the Kadec-Klee property of $E$, we obtain

$$
\lim _{n \rightarrow \infty} u_{n}=\widehat{p}
$$

Step 6. We will show that $\widehat{p} \in \Omega$.

Substep 1. We will show that $\widehat{p} \in \bigcap_{n=1}^{N} \operatorname{VI}\left(C, A_{n}\right)$.

From the definition of $K_{r_{n}}$ of algorithm (32), we have

$$
\left\langle y-z_{n}, A_{n} z_{n}\right\rangle+\frac{1}{r_{n}}\left\langle y-z_{n}, J z_{n}-J x_{n}\right\rangle \geq 0, \quad \forall y \in C .
$$

Let $\left\{n_{k}\right\}_{k \in \mathbb{N}} \subset \mathbb{N}$ be such that $A_{n_{k}}=A_{1}$, for all $k \in \mathbb{N}$. Then from (61), we obtain

$$
\left\langle y-z_{n_{k}}, A_{1} z_{n_{k}}\right\rangle+\frac{1}{r_{n_{k}}}\left\langle y-z_{n_{k}}, J z_{n_{k}}-J x_{n_{k}}\right\rangle \geq 0, \quad \forall y \in C,
$$

and that is

$$
\left\langle y-z_{n_{k}}, A_{1} z_{n_{k}}\right\rangle+\left\langle y-z_{n_{k}}, \frac{J z_{n_{k}}-J x_{n_{k}}}{r_{n_{k}}}\right\rangle \geq 0, \quad \forall y \in C .
$$

Now, we set $v_{t}=t v+(1-t) \widehat{p}$, for all $t \in(0,1]$ and $v \in C$.

Therefore, we get $v_{t} \in C$. From (63), it follows that

$$
\begin{aligned}
\left\langle v_{t}-z_{n_{k}}, A_{1} v_{t}\right\rangle \geq & \left\langle v_{t}-z_{n_{k}}, A_{1} v_{t}\right\rangle-\left\langle v_{t}-z_{n_{k}}, A_{1} z_{n_{k}}\right\rangle \\
& -\left\langle v_{t}-z_{n_{k}}, \frac{J z_{n_{k}}-J x_{n_{k}}}{r_{n_{k}}}\right\rangle \\
= & \left\langle v_{t}-z_{n_{k}}, A_{1} v_{t}-A_{1} z_{n_{k}}\right\rangle \\
& -\left\langle v_{t}-z_{n_{k}}, \frac{J z_{n_{k}}-J x_{n_{k}}}{r_{n_{k}}}\right\rangle .
\end{aligned}
$$

From the continuity of $J$ and (41) and (54), we have $x_{n_{k}} \rightarrow \widehat{p}$, $z_{n_{k}} \rightarrow \widehat{p}$, as $k \rightarrow \infty$, we obtain

$$
\frac{J z_{n_{k}}-J x_{n_{k}}}{r_{n_{k}}} \longrightarrow 0, \quad \text { as } k \longrightarrow \infty \text {. }
$$

Since $A_{1}$ is a monotone mapping, we also have $\left\langle v_{t}-z_{n_{k}}, A_{1} v_{t}-\right.$ $\left.A_{1} z_{n_{k}}\right\rangle \geq 0$.

Thus, it follows that

$$
\begin{aligned}
0 & \leq \lim _{n \rightarrow \infty}\left\langle v_{t}-z_{n_{k}}, A_{1} v_{t}\right\rangle \\
& =\left\langle v_{t}-\widehat{p}, A_{1} v_{t}\right\rangle,
\end{aligned}
$$


and hence

$$
\left\langle y-\widehat{p}, A_{1} v_{t}\right\rangle \geq 0, \quad \forall y \in C
$$

If $t \rightarrow 0$, we obtain

$$
\left\langle y-\widehat{p}, A_{1} \widehat{p}\right\rangle \geq 0, \quad \forall y \in C
$$

This implies that $\widehat{p} \in \operatorname{VI}\left(C, A_{1}\right)$. $k \in \mathbb{N}$.

Similarly, let $\left\{n_{k}\right\}_{k \in \mathbb{N}} \subset \mathbb{N}$ be such that $A_{n_{k}}=A_{2}$, for all

Then, we have again that $\widehat{p} \in \operatorname{VI}\left(C, A_{2}\right)$.

Continuing in the same way, we obtain that $\widehat{p} \in$ $\mathrm{VI}\left(C, A_{n}\right)$, where $n=3,4,5, \ldots, N$.

Hence, $\widehat{p} \in \bigcap_{n=1}^{N} \operatorname{VI}\left(C, A_{n}\right)$.

Substep 2. We will show that $\hat{p} \in \bigcap_{k=1}^{M} \operatorname{SEP}\left(F_{k}\right)$.

From the definition of $T_{r_{n}}$ of algorithm (32) and (A2), we have

$$
\frac{1}{r_{n}}\left\langle y-u_{n}, J u_{n}-J x_{n}\right\rangle \geq-F_{n}\left(u_{n}, y\right) \geq F\left(y, u_{n}\right), \quad \forall y \in C .
$$

Let $\left\{n_{k}\right\}_{k \in \mathbb{N}} \subset \mathbb{N}$ be such that $F_{n_{k}}=F_{1}$, for all $k \in \mathbb{N}$. Then from (69), we obtain

$$
\begin{aligned}
\frac{1}{r_{n_{k}}}\left\langle y-u_{n_{k}}, J u_{n_{k}}-J x_{n_{k}}\right\rangle & =\left\langle y-u_{n_{k}}, \frac{J u_{n_{k}}-J x_{n_{k}}}{r_{n_{k}}}\right\rangle \\
& \geq F_{1}\left(y, u_{n_{k}}\right), \quad \forall y \in C .
\end{aligned}
$$

From the continuity of $J$ and (41) and (60), we have $x_{n_{k}} \rightarrow \widehat{p}$, $u_{n_{k}} \rightarrow \widehat{p}$, as $k \rightarrow \infty$ and we obtain

$$
\frac{J u_{n_{k}}-J x_{n_{k}}}{r_{n_{k}}} \longrightarrow 0, \quad \text { as } k \longrightarrow \infty
$$

Therefore, $F_{1}\left(y, u_{n_{k}}\right) \leq 0, \forall y \in C$.

Now, we set $w_{t}=t w+(1-t) \hat{p}$, for all $t \in(0,1]$ and $w \in C$.

Consequently, we get $w_{t} \in C$. And so $F_{1}\left(w_{t}, \widehat{p}\right) \leq 0$.

Therefore, from (A1), we obtain

$$
\begin{aligned}
0 & =F_{1}\left(w_{t}, w_{t}\right) \\
& \leq t F_{1}\left(w_{t}, y\right)+(1-t) F_{1}\left(w_{t}, \widehat{p}\right) \\
& \leq t F_{1}\left(w_{t}, y\right) .
\end{aligned}
$$

Thus, $F_{1}\left(w_{t}, y\right) \geq 0, \forall y \in C$. From (A3), if $t \rightarrow 0$, then we get $F_{1}(\widehat{p}, y) \geq 0, \forall y \in C$. This implies that $\widehat{p} \in \operatorname{EP}\left(F_{1}\right)$.

Similarly, let $\left\{n_{k}\right\}_{k \in \mathbb{N}} \subset \mathbb{N}$ be such that $F_{n_{k}}=F_{2}$, for all $k \in \mathbb{N}$. Then, we have again that $\widehat{p} \in \operatorname{EP}\left(F_{2}\right)$.

Continuing in the same way, we obtain that $\widehat{p} \in \operatorname{EP}\left(F_{k}\right)$, where $k=3,4,5, \ldots, M$. Hence, $\widehat{p} \in \bigcap_{k=1}^{M} \operatorname{SEP}\left(F_{k}\right)$.

Substep 3. We will show that $\widehat{p} \in \bigcap_{i=1}^{D} F\left(S_{i}\right)$.
From algorithm (32) and Lemma 12, we compute

$$
\begin{aligned}
& \phi\left(p, y_{n}\right)=\phi\left(p, J^{-1}\left(\alpha J x_{n}+\beta J T_{n} z_{n}+\gamma J S_{n} u_{n}\right)\right) \\
& =\|p\|^{2}-2\left\langle p, \alpha J x_{n}+\beta J T_{n} z_{n}+\gamma J S_{n} u_{n}\right\rangle \\
& +\left\|\alpha J x_{n}+\beta J T_{n} z_{n}+\gamma J S_{n} u_{n}\right\|^{2} \\
& \leq\|p\|^{2}-2 \alpha\left\langle p, J x_{n}\right\rangle-2 \beta\left\langle p, J T_{n} z_{n}\right\rangle \\
& -2 \gamma\left\langle p, J S_{n} u_{n}\right\rangle+\alpha\left\|x_{n}\right\|^{2}+\beta\left\|T_{n} z_{n}\right\|^{2} \\
& +\gamma\left\|S_{n} u_{n}\right\|^{2}-\alpha \beta g\left(\left\|J x_{n}-J T_{n} z_{n}\right\|\right) \\
& -\alpha \gamma g\left(\left\|J x_{n}-J S_{n} u_{n}\right\|\right) \\
& =\alpha \phi\left(p, x_{n}\right)+\beta \phi\left(p, T_{n} z_{n}\right)+\gamma \phi\left(p, S_{n} u_{n}\right) \\
& -\alpha \beta g\left(\left\|J x_{n}-J T_{n} z_{n}\right\|\right)-\alpha \gamma g\left(\left\|J x_{n}-J S_{n} u_{n}\right\|\right) \\
& \leq \alpha \phi\left(p, x_{n}\right)+\beta \phi\left(p, z_{n}\right)+\gamma \phi\left(p, u_{n}\right) \\
& -\alpha \beta g\left(\left\|J x_{n}-J T_{n} z_{n}\right\|\right)-\alpha \gamma g\left(\left\|J x_{n}-J S_{n} u_{n}\right\|\right) \\
& =\alpha \phi\left(p, x_{n}\right)+\beta \phi\left(p, K_{r_{n}} x_{n}\right)+\gamma \phi\left(p, T_{r_{n}} x_{n}\right) \\
& -\alpha \beta g\left(\left\|J x_{n}-J T_{n} z_{n}\right\|\right)-\alpha \gamma g\left(\left\|J x_{n}-J S_{n} u_{n}\right\|\right) \\
& \leq \alpha \phi\left(p, x_{n}\right)+\beta \phi\left(p, x_{n}\right)+\gamma \phi\left(p, x_{n}\right) \\
& -\alpha \beta g\left(\left\|J x_{n}-J T_{n} z_{n}\right\|\right)-\alpha \gamma g\left(\left\|J x_{n}-J S_{n} u_{n}\right\|\right) \\
& =(\alpha+\beta+\gamma) \phi\left(p, x_{n}\right) \\
& -\alpha \beta g\left(\left\|J x_{n}-J T_{n} z_{n}\right\|\right) \\
& -\alpha \gamma g\left(\left\|J x_{n}-J S_{n} u_{n}\right\|\right) \\
& =\phi\left(p, x_{n}\right)-\alpha \beta g\left(\left\|J x_{n}-J T_{n} z_{n}\right\|\right) \\
& -\alpha \gamma g\left(\left\|J x_{n}-J S_{n} u_{n}\right\|\right) \\
& \leq \phi\left(p, x_{n}\right) \text {. }
\end{aligned}
$$

From (73), we have

$$
\begin{aligned}
\phi\left(p, y_{n}\right) \leq & \phi\left(p, x_{n}\right)-\alpha \beta g\left(\left\|J x_{n}-J T_{n} z_{n}\right\|\right) \\
& -\alpha \gamma g\left(\left\|J x_{n}-J S_{n} u_{n}\right\|\right) \\
\leq & \phi\left(p, x_{n}\right)-\alpha \gamma g\left(\left\|J x_{n}-J S_{n} u_{n}\right\|\right) .
\end{aligned}
$$

From $x_{n} \rightarrow \widehat{p}, y_{n} \rightarrow \widehat{p}$, and $\alpha, \gamma>0$, we obtain

$$
\begin{aligned}
& \alpha \gamma g\left(\left\|J x_{n}-J S_{n} u_{n}\right\|\right) \\
& \quad \leq \phi\left(p, x_{n}\right)-\phi\left(p, y_{n}\right) \longrightarrow 0, \quad \text { as } n \longrightarrow \infty .
\end{aligned}
$$

Therefore,

$$
g\left(\left\|J x_{n}-J S_{n} u_{n}\right\|\right) \longrightarrow 0, \quad \text { as } n \longrightarrow \infty .
$$


It follows from the property of $g$ that

$$
\left\|J x_{n}-J S_{n} u_{n}\right\| \longrightarrow 0, \quad \text { as } n \longrightarrow \infty \text {. }
$$

From (42), we have $J x_{n} \rightarrow J \widehat{p}$, as $n \rightarrow \infty$. Then,

$$
J S_{n} u_{n} \longrightarrow J \hat{p}, \quad \text { as } n \longrightarrow \infty
$$

and so

$$
\left\|S_{n} u_{n}\right\| \longrightarrow\|\hat{p}\|, \quad \text { as } n \longrightarrow \infty
$$

Moreover, the demicontinuity of $J^{-1}$ implies that $S_{n} u_{n} \rightarrow \widehat{p}$ as $n \rightarrow \infty$. Thus, the Kadec-Klee property of $E$, we obtain

$$
S_{n} u_{n} \longrightarrow \widehat{p}, \quad \text { as } n \longrightarrow \infty \text {. }
$$

Let $\left\{n_{k}\right\}_{k \in \mathbb{N}} \subset \mathbb{N}$ be such that $S_{n_{k}}=S_{1}$, for all $k \in \mathbb{N}$.

Then, from (60), we have $u_{n_{k}} \rightarrow \widehat{p}$, as $n \rightarrow \infty$. It follows from (80) and the closedness of $S_{1}$ that

$$
\widehat{p}=\lim _{k \rightarrow \infty} S_{n_{k}} u_{n_{k}}=\lim _{k \rightarrow \infty} S_{1} u_{n_{k}}=S_{1} \widehat{p}
$$

This implies that $\widehat{p} \in F\left(S_{1}\right)$.

Similarly, let $\left\{n_{k}\right\}_{k \in \mathbb{N}} \subset \mathbb{N}$ be such that $S_{n_{k}}=S_{2}$, for all $k \in \mathbb{N}$. Then, we have again that $\widehat{p} \in F\left(S_{2}\right)$.

Continuing in the same way, we obtain that $\widehat{p} \in F\left(S_{i}\right)$, where $i=3,4,5, \ldots, D$.

Hence, $\widehat{p} \in \bigcap_{i=1}^{D} F\left(S_{i}\right)$.

Substep 4. We will show that $\widehat{p} \in \bigcap_{i=1}^{D} F\left(T_{i}\right)$.

From (73), we have

$$
\begin{aligned}
\phi\left(p, y_{n}\right) \leq & \phi\left(p, x_{n}\right)-\alpha \beta g\left(\left\|J x_{n}-J T_{n} z_{n}\right\|\right) \\
& -\alpha \gamma g\left(\left\|J x_{n}-J S_{n} u_{n}\right\|\right) \\
\leq & \phi\left(p, x_{n}\right)-\alpha \beta g\left(\left\|J x_{n}-J T_{n} z_{n}\right\|\right) .
\end{aligned}
$$

From $x_{n} \rightarrow \widehat{p}, y_{n} \rightarrow \widehat{p}$, and $\alpha, \beta>0$, we obtain

$$
\begin{aligned}
& \alpha \beta g\left(\left\|J x_{n}-J T_{n} z_{n}\right\|\right) \\
& \quad \leq \phi\left(p, x_{n}\right)-\phi\left(p, y_{n}\right) \longrightarrow 0, \quad \text { as } n \longrightarrow \infty .
\end{aligned}
$$

Therefore,

$$
g\left(\left\|J x_{n}-J T_{n} z_{n}\right\|\right) \longrightarrow 0, \quad \text { as } n \longrightarrow \infty .
$$

It follows from the property of $g$ that

$$
\left\|J x_{n}-J T_{n} z_{n}\right\| \longrightarrow 0, \quad \text { as } n \longrightarrow \infty .
$$

From (42), we have $J x_{n} \rightarrow J \widehat{p}$, as $n \rightarrow \infty$. Then,

$$
J T_{n} z_{n} \longrightarrow J \widehat{p}, \quad \text { as } n \longrightarrow \infty
$$

and so

$$
\left\|T_{n} z_{n}\right\| \longrightarrow\|\hat{p}\|, \quad \text { as } n \longrightarrow \infty \text {. }
$$

Moreover, the demicontinuity of $J^{-1}$ implies that $T_{n} z_{n} \rightarrow \widehat{p}$ as $n \rightarrow \infty$. Thus, the Kadec-Klee property of $E$, we obtain

$$
T_{n} z_{n} \longrightarrow \widehat{p}, \quad \text { as } n \longrightarrow \infty \text {. }
$$

Let $\left\{n_{k}\right\}_{k \in \mathbb{N}} \subset \mathbb{N}$ be such that $T_{n_{k}}=T_{1}$, for all $k \in \mathbb{N}$.

Then, from (54), we have $z_{n_{k}} \rightarrow \widehat{p}$, as $n \rightarrow \infty$. It follows from (88) and the closedness of $T_{1}$ that

$$
\widehat{p}=\lim _{k \rightarrow \infty} T_{n_{k}} z_{n_{k}}=\lim _{k \rightarrow \infty} T_{1} z_{n_{k}}=T_{1} \widehat{p}
$$

This implies that $\widehat{p} \in F\left(T_{1}\right)$.

Similarly, let $\left\{n_{k}\right\}_{k \in \mathbb{N}} \subset \mathbb{N}$ be such that $T_{n_{k}}=T_{2}$, for all $k \in \mathbb{N}$. Then, we have again that $\widehat{p} \in F\left(T_{2}\right)$.

Continuing in the same way, we obtain that $\widehat{p} \in F\left(T_{i}\right)$, where $i=3,4,5, \ldots, D$.

Hence, $\widehat{p} \in \bigcap_{i=1}^{D} F\left(T_{i}\right)$.

From Substeps (6.1)-(6.4), we can conclude that

$$
\begin{aligned}
\widehat{p} \in \Omega:= & \left(\bigcap_{i=1}^{D} F\left(T_{i}\right)\right) \bigcap\left(\bigcap_{i=1}^{D} F\left(S_{i}\right)\right) \bigcap\left(\bigcap_{k=1}^{M} \operatorname{SEP}\left(F_{k}\right)\right) \\
& \bigcap\left(\bigcap_{n=1}^{N} \operatorname{VI}\left(C, A_{n}\right)\right) .
\end{aligned}
$$

Step 7. Finally, we will show that $\widehat{p}=\Pi_{\Omega}\left(x_{0}\right)$.

From $x_{n}=\Pi_{C_{n}}\left(x_{0}\right)$, we have

$$
\left\langle J x_{0}-J x_{n}, x_{n}-p\right\rangle \geq 0, \quad \forall p \in \Omega .
$$

Taking $n \rightarrow \infty$ in (91), one has

$$
\left\langle J x_{0}-J \widehat{p}, \widehat{p}-p\right\rangle \geq 0, \quad \forall p \in \Omega \text {. }
$$

Now, we have $\widehat{p} \in \Omega$ and by Lemma 5, we get

$$
\widehat{p}=\Pi_{\Omega}\left(x_{0}\right) .
$$

This completes the proof of Theorem 13.

If we set $M=N=D=1$ in Theorem 13, then we obtain the following result.

Corollary 14. Let $C$ be a nonempty, closed and convex subset of a uniformly smooth and strictly convex real Banach space $E$ which has the Kadec-Klee property. Suppose that

(1) $F: C \times C \rightarrow \mathbb{R}$ is a bifunction satisfying conditions (A1)-(A4);

(2) $T$ and $S$ are two quasi- $\phi$-nonexpansive mappings from $C$ into $E$;

(3) $A: C \rightarrow E^{*}$ is a continuous monotone mapping. 
(4) For $x \in E$, one defines the mappings $K_{r_{n}}, T_{r_{n}}: E \rightarrow C$ as follows:

$$
\begin{aligned}
K_{r_{n}}(x):= & \{z \in C:\langle y-z, A z\rangle \\
& \left.+\frac{1}{r_{n}}\langle y-z, J z-J x\rangle \geq 0, \forall y \in C\right\} ; \\
T_{r_{n}}(x):= & \{z \in C: F(z, y) \\
& \left.+\frac{1}{r_{n}}\langle y-z, J z-J x\rangle \geq 0, \forall y \in C\right\} .
\end{aligned}
$$

Assume that $\Omega:=F(T) \cap F(S) \cap \operatorname{EP}(F) \cap \mathrm{VI}(C, A)$ is a nonempty and bounded in $C$ and let $\left\{x_{n}\right\}$ be a sequence generated by

$$
\begin{gathered}
x_{0} \in C_{0}=C, \text { chosen arbitrary, } \\
z_{n}=K_{r_{n}} x_{n}, \\
u_{n}=T_{r_{n}} x_{n}, \\
y_{n}=J^{-1}\left(\alpha J x_{n}+\beta J T z_{n}+\gamma J S u_{n}\right), \\
C_{n+1}=\left\{z \in C_{n}: \phi\left(z, y_{n}\right) \leq \phi\left(z, x_{n}\right)\right\}, \\
x_{n+1}=\Pi_{C_{n+1}}\left(x_{0}\right), \quad \forall n \geq 0,
\end{gathered}
$$

where $\left\{r_{n}\right\} \subset[a, \infty)$ for some $a>0$ and $n \in \mathbb{N}$, and $\alpha, \beta$, $\gamma$ are real numbers in $(0,1)$ such that $\alpha+\beta+\gamma=1$.

Then, the sequence $\left\{x_{n}\right\}_{n=0}^{\infty}$ converges strongly to $\hat{p}=$ $\Pi_{\Omega}\left(x_{0}\right)$.

If we set $T_{i}=I$, for any $i=1,2,3, \ldots, D$ in Theorem 13, then we obtain the following result which extends and improves the result's Zegeye and Shahzad [7].

Corollary 15 (Zegeye and Shahzad [7]). Let C be a nonempty, closed and convex subset of a uniformly smooth and strictly convex real Banach space $E$ which has Kadec-Klee property. Suppose that

(1) $\left\{F_{k}\right\}_{k=1}^{M}: C \times C \rightarrow \mathbb{R}$ is a finite family of bifunctions satisfying conditions (A1)-(A4), where $k=1,2$, $3, \ldots, M$;

(2) $\left\{S_{i}\right\}_{i=1}^{D}: C \rightarrow E$ is a finite family of quasi- $\phi$-nonexpansive mappings, where $i=1,2,3, \ldots, D$;

(3) $\left\{A_{n}\right\}_{n=1}^{N}: C \rightarrow E^{*}$ is a finite family of continuous monotone mappings, where $n=1,2,3, \ldots, N$;
(4) For $x \in E$, one defines the mappings $K_{r_{n}}, T_{r_{n}}: E \rightarrow C$ by

$$
\begin{aligned}
K_{r_{n}}(x):= & \left\{z \in C:\left\langle y-z, A_{n} z\right\rangle\right. \\
& \left.+\frac{1}{r_{n}}\langle y-z, J z-J x\rangle \geq 0, \forall y \in C\right\} ; \\
T_{r_{n}}(x):= & \left\{z \in C: F_{n}(z, y)\right. \\
& \left.+\frac{1}{r_{n}}\langle y-z, J z-J x\rangle \geq 0, \forall y \in C\right\} .
\end{aligned}
$$

Assume that $\Omega:=\left(\bigcap_{i=1}^{D} F\left(S_{i}\right)\right) \bigcap\left(\bigcap_{k=1}^{M} \operatorname{SEP}\left(F_{k}\right)\right) \bigcap\left(\bigcap_{n=1}^{N}\right.$ $\left.\mathrm{VI}\left(C, A_{n}\right)\right)$ is a nonempty and bounded in $C$ and let $\left\{x_{n}\right\}$ be a sequence generated by

$$
\begin{gathered}
x_{0} \in C_{0}=C, \text { chosen arbitrary, } \\
z_{n}=K_{r_{n}} x_{n}, \\
u_{n}=T_{r_{n}} x_{n}, \\
y_{n}=J^{-1}\left(\alpha J x_{n}+\beta J z_{n}+\gamma J S_{n} u_{n}\right), \\
C_{n+1}=\left\{z \in C_{n}: \phi\left(z, y_{n}\right) \leq \phi\left(z, x_{n}\right)\right\}, \\
x_{n+1}=\Pi_{C_{n+1}}\left(x_{0}\right), \quad \forall n \geq 0,
\end{gathered}
$$

where $A_{n} \equiv A_{n}(\bmod N), F_{n} \equiv F_{n}(\bmod M), S_{n} \equiv S_{n}(\bmod$ $D),\left\{r_{n}\right\} \subset[a, \infty)$ for some $a>0$ and $n \in \mathbb{N}$, and $\alpha, \beta, \gamma$ are real numbers in $(0,1)$ such that $\alpha+\beta+\gamma=1$.

Then, the sequence $\left\{x_{n}\right\}_{n=0}^{\infty}$ converges strongly to $\widehat{p}=$ $\Pi_{\Omega}\left(x_{0}\right)$.

\section{Deduced Theorems}

If we set $F_{k} \equiv 0$, for any $k=1,2,3, \ldots, M$ in Theorem 13 , then we obtain the following result.

Corollary 16. Let $C$ be a nonempty, closed and convex subset of a uniformly smooth and strictly convex real Banach space $E$ which has the Kadec-Klee property. Suppose that

(1) $\left\{T_{i}\right\}_{i=1}^{D}$ and $\left\{S_{i}\right\}_{i=1}^{D}$ are finite families of quasi- $\phi$-nonexpansive mappings from $C$ into $E$, where $i=$ $1,2,3, \ldots, D$

(2) $\left\{A_{n}\right\}_{n=1}^{N}: C \rightarrow E^{*}$ is a finite family of continuous monotone mappings, where $n=1,2,3, \ldots, N$;

(3) For $x \in E$, we define the mappings $K_{r_{n}}: E \rightarrow C$ by

$$
\begin{aligned}
K_{r_{n}}(x):= & \left\{z \in C:\left\langle y-z, A_{n} z\right\rangle\right. \\
& \left.+\frac{1}{r_{n}}\langle y-z, J z-J x\rangle \geq 0, \forall y \in C\right\} .
\end{aligned}
$$


Assume that $\Omega:=\left(\bigcap_{i=1}^{D} F\left(T_{i}\right)\right) \bigcap\left(\bigcap_{i=1}^{D} F\left(S_{i}\right)\right) \bigcap\left(\bigcap_{n=1}^{N}\right.$ $\left.\mathrm{VI}\left(C, A_{n}\right)\right)$ is a nonempty and bounded in $C$ and let $\left\{x_{n}\right\}$ be a sequence generated by

$$
\begin{gathered}
x_{0} \in C_{0}=C, \text { chosen arbitrary, } \\
z_{n}=K_{r_{n}} x_{n}, \\
y_{n}=J^{-1}\left(\alpha J x_{n}+\beta J T_{n} z_{n}+\gamma J S_{n} x_{n}\right), \\
C_{n+1}=\left\{z \in C_{n}: \phi\left(z, y_{n}\right) \leq \phi\left(z, x_{n}\right)\right\}, \\
x_{n+1}=\Pi_{C_{n+1}}\left(x_{0}\right), \quad \forall n \geq 0,
\end{gathered}
$$

where $A_{n} \equiv A_{n}(\bmod N), T_{n} \equiv T_{n}(\bmod D), S_{n} \equiv S_{n}(\bmod$ $D),\left\{r_{n}\right\} \subset[a, \infty)$ for some $a>0$ and $n \in \mathbb{N}$, and $\alpha, \beta, \gamma$ are real numbers in $(0,1)$ such that $\alpha+\beta+\gamma=1$.

Then, the sequence $\left\{x_{n}\right\}_{n=0}^{\infty}$ converges strongly to $\widehat{p}=$ $\Pi_{\Omega}\left(x_{0}\right)$.

If we set $A_{n} \equiv 0$, for any $n=1,2,3, \ldots, N$ in Theorem 13 , then we obtain the following result.

Corollary 17. Let $C$ be a nonempty, closed and convex subset of a uniformly smooth and strictly convex real Banach space $E$ which has the Kadec-Klee property. Suppose that

(1) $\left\{F_{k}\right\}_{k=1}^{M}: C \times C \rightarrow \mathbb{R}$ is a finite family of bifunctions satisfying conditions (A1)-(A4), where $k=1,2$, $3, \ldots, M$;

(2) $\left\{T_{i}\right\}_{i=1}^{D}$ and $\left\{S_{i}\right\}_{i=1}^{D}$ are finite families of quasi- $\phi$-nonexpansive mappings from $C$ into $E$, where $i=1,2$, $3, \ldots, D$

(3) For $x \in E$, one defines the mappings $T_{r_{n}}: E \rightarrow C$ by

$$
\begin{aligned}
T_{r_{n}}(x):= & \left\{z \in C: F_{n}(z, y)\right. \\
& \left.+\frac{1}{r_{n}}\langle y-z, J z-J x\rangle \geq 0, \forall y \in C\right\} .
\end{aligned}
$$

Assume that $\Omega:=\left(\bigcap_{i=1}^{D} F\left(T_{i}\right)\right) \bigcap\left(\bigcap_{i=1}^{D} F\left(S_{i}\right)\right) \bigcap\left(\bigcap_{k=1}^{M}\right.$ $\operatorname{SEP}\left(F_{k}\right)$ ) is a nonempty and bounded in $C$ and let $\left\{x_{n}\right\}$ be a sequence generated by

$$
\begin{gathered}
x_{0} \in C_{0}=C, \text { chosen arbitrary, } \\
u_{n}=T_{r_{n}} x_{n}, \\
y_{n}=J^{-1}\left(\alpha J x_{n}+\beta J T_{n} x_{n}+\gamma J S_{n} u_{n}\right), \\
C_{n+1}=\left\{z \in C_{n}: \phi\left(z, y_{n}\right) \leq \phi\left(z, x_{n}\right)\right\}, \\
x_{n+1}=\prod_{C_{n+1}}\left(x_{0}\right), \quad \forall n \geq 0,
\end{gathered}
$$

where $F_{n} \equiv F_{n}(\bmod M), T_{n} \equiv T_{n}(\bmod D), S_{n} \equiv S_{n}(\bmod$ $D),\left\{r_{n}\right\} \subset[a, \infty)$ for some $a>0$ and $n \in \mathbb{N}$, and $\alpha, \beta, \gamma$ are real numbers in $(0,1)$ such that $\alpha+\beta+\gamma=1$.

Then, the sequence $\left\{x_{n}\right\}_{n=0}^{\infty}$ converges strongly to $\widehat{p}=$ $\Pi_{\Omega}\left(x_{0}\right)$.
If we set $F_{k} \equiv 0$, for any $k=1,2,3, \ldots, M$ and $A_{n} \equiv 0$, for any $n=1,2,3, \ldots, N$ in Theorem 13 , then we obtain the following result.

Corollary 18. Let $C$ be a nonempty, closed and convex subset of a uniformly smooth and strictly convex real Banach space $E$ which has the Kadec-Klee property. Suppose that $\left\{T_{i}\right\}_{i=1}^{D}$ and $\left\{S_{i}\right\}_{i=1}^{D}$ are finite families of quasi- $\phi$-nonexpansive mappings from $C$ into $E$, where $i=1,2,3, \ldots, D$.

Assume that $\Omega:=\left(\bigcap_{i=1}^{D} F\left(T_{i}\right)\right) \bigcap\left(\bigcap_{i=1}^{D} F\left(S_{i}\right)\right)$ is a nonempty and bounded in $C$ and let $\left\{x_{n}\right\}$ be a sequence generated by

$$
\begin{gathered}
x_{0} \in C_{0}=C, \text { chosen arbitrary, } \\
y_{n}=J^{-1}\left(\alpha J x_{n}+\beta J T_{n} x_{n}+\gamma J S_{n} x_{n}\right), \\
C_{n+1}=\left\{z \in C_{n}: \phi\left(z, y_{n}\right) \leq \phi\left(z, x_{n}\right)\right\}, \\
x_{n+1}=\Pi_{C_{n+1}}\left(x_{0}\right), \quad \forall n \geq 0,
\end{gathered}
$$

where $T_{n} \equiv T_{n}(\bmod D), S_{n} \equiv S_{n}(\bmod D),\left\{r_{n}\right\} \subset[a, \infty)$ for some $a>0$ and $n \in \mathbb{N}$, and $\alpha, \beta, \gamma$ are real numbers in $(0,1)$ such that $\alpha+\beta+\gamma=1$.

Then, the sequence $\left\{x_{n}\right\}_{n=0}^{\infty}$ converges strongly to $\hat{p}=$ $\Pi_{\Omega}\left(x_{0}\right)$

\section{Some Applications}

5.1. Application to Weak Relatively Nonexpansive Mappings. If we change the condition (2) in Theorem 13 as follows: $\left\{T_{i}\right\}_{i=1}^{D}$ and $\left\{S_{i}\right\}_{i=1}^{D}$ are finite families of weak relatively nonexpansive mappings. From Remark 2(2), every weak relatively nonexpansive mappings is quasi- $\phi$-nonexpansive mappings. Then, we obtain the following result.

Corollary 19. Let $C$ be a nonempty, closed and convex subset of a uniformly smooth and strictly convex real Banach space $E$ which has the Kadec-Klee property. Suppose that

(1) $\left\{F_{k}\right\}_{k=1}^{M}: C \times C \rightarrow \mathbb{R}$ is a finite family of bifunctions satisfying conditions $(A 1)-(A 4)$, where $k=$ $1,2,3, \ldots, M$;

(2) $\left\{T_{i}\right\}_{i=1}^{D}$ and $\left\{S_{i}\right\}_{i=1}^{D}$ are finite families of weak relatively nonexpansive mappings from $C$ into $E$, where $i=$ $1,2,3, \ldots, D$

(3) $\left\{A_{n}\right\}_{n=1}^{N}: C \rightarrow E^{*}$ is a finite family of continuous monotone mappings, where $n=1,2,3, \ldots, N$; 
(4) For $x \in E$, one defines the mappings $K_{r_{n}}, T_{r_{n}}: E \rightarrow C$ by

$$
\begin{aligned}
K_{r_{n}}(x):= & \left\{z \in C:\left\langle y-z, A_{n} z\right\rangle\right. \\
& \left.+\frac{1}{r_{n}}\langle y-z, J z-J x\rangle \geq 0, \forall y \in C\right\} ; \\
T_{r_{n}}(x):= & \left\{z \in C: F_{n}(z, y)\right. \\
& \left.+\frac{1}{r_{n}}\langle y-z, J z-J x\rangle \geq 0, \forall y \in C\right\} .
\end{aligned}
$$

Assume that $\Omega:=\left(\bigcap_{i=1}^{D} F\left(T_{i}\right)\right) \bigcap\left(\bigcap_{i=1}^{D} F\left(S_{i}\right)\right) \bigcap\left(\bigcap_{k=1}^{M}\right.$ $\left.\operatorname{SEP}\left(F_{k}\right)\right) \cap\left(\cap_{n=1}^{N} \operatorname{VI}\left(C, A_{n}\right)\right)$ is a nonempty and bounded in $C$ and let $\left\{x_{n}\right\}$ be a sequence generated by

$$
\begin{gathered}
x_{0} \in C_{0}=C, \text { chosen arbitrary, } \\
z_{n}=K_{r_{n}} x_{n}, \\
u_{n}=T_{r_{n}} x_{n}, \\
y_{n}=J^{-1}\left(\alpha J x_{n}+\beta J T_{n} z_{n}+\gamma J S_{n} u_{n}\right), \\
C_{n+1}=\left\{z \in C_{n}: \phi\left(z, y_{n}\right) \leq \phi\left(z, x_{n}\right)\right\}, \\
x_{n+1}=\Pi_{C_{n+1}}\left(x_{0}\right), \quad \forall n \geq 0,
\end{gathered}
$$

where $A_{n} \equiv A_{n}(\bmod N), F_{n} \equiv F_{n}(\bmod M), T_{n} \equiv T_{n}(\bmod$ $D), S_{n} \equiv S_{n}(\bmod D),\left\{r_{n}\right\} \subset[a, \infty)$ for some $a>0$ and $n \in$ $\mathbb{N}$, and $\alpha, \beta, \gamma$ are real numbers in $(0,1)$ such that $\alpha+\beta+\gamma=1$.

Then, the sequence $\left\{x_{n}\right\}_{n=0}^{\infty}$ converges strongly to $\widehat{p}=$ $\Pi_{\Omega}\left(x_{0}\right)$.

5.2. Application to Relatively Nonexpansive Mappings. If we change the condition (2) in Theorem 13 as follows: $\left\{T_{i}\right\}_{i=1}^{D}$ and $\left\{S_{i}\right\}_{i=1}^{D}$ are finite families of relatively nonexpansive mappings. From Remark 2(3) and (2) every relatively nonexpansive mappings is weak relatively nonexpansive mappings and every weak relatively nonexpansive mappings is quasi- $\phi$ nonexpansive mappings. Then, we obtain the following result.

Corollary 20. Let $C$ be a nonempty, closed and convex subset of a uniformly smooth and strictly convex real Banach space $E$ which has the Kadec-Klee property. Suppose that

(1) $\left\{F_{k}\right\}_{k=1}^{M}: C \times C \rightarrow \mathbb{R}$ is a finite family of bifunctions satisfying conditions (A1)-(A4), where $k=$ $1,2,3, \ldots, M$;

(2) $\left\{T_{i}\right\}_{i=1}^{D}$ and $\left\{S_{i}\right\}_{i=1}^{D}$ are finite families of relatively nonexpansive mappings from $C$ into $E$, where $i=1,2$, $3, \ldots, D$

(3) $\left\{A_{n}\right\}_{n=1}^{N}: C \rightarrow E^{*}$ is a finite family of continuous monotone mappings, where $n=1,2,3, \ldots, N$;
(4) For $x \in E$, one defines the mappings $K_{r_{n}}, T_{r_{n}}: E \rightarrow C$ by

$$
\begin{aligned}
K_{r_{n}}(x):= & \left\{z \in C:\left\langle y-z, A_{n} z\right\rangle\right. \\
& \left.+\frac{1}{r_{n}}\langle y-z, J z-J x\rangle \geq 0, \forall y \in C\right\} ; \\
T_{r_{n}}(x):= & \left\{z \in C: F_{n}(z, y)\right. \\
& \left.+\frac{1}{r_{n}}\langle y-z, J z-J x\rangle \geq 0, \forall y \in C\right\} .
\end{aligned}
$$

Assume that $\Omega:=\left(\bigcap_{i=1}^{D} F\left(T_{i}\right)\right) \bigcap\left(\bigcap_{i=1}^{D} F\left(S_{i}\right)\right) \cap\left(\bigcap_{k=1}^{M}\right.$ $\left.\operatorname{SEP}\left(F_{k}\right)\right) \cap\left(\cap_{n=1}^{N} \operatorname{VI}\left(C, A_{n}\right)\right)$ is a nonempty and bounded in $C$ and let $\left\{x_{n}\right\}$ be a sequence generated by

$$
\begin{gathered}
x_{0} \in C_{0}=C, \text { chosen arbitrary, } \\
z_{n}=K_{r_{n}} x_{n}, \\
u_{n}=T_{r_{n}} x_{n}, \\
y_{n}=J^{-1}\left(\alpha J x_{n}+\beta J T_{n} z_{n}+\gamma J S_{n} u_{n}\right), \\
C_{n+1}=\left\{z \in C_{n}: \phi\left(z, y_{n}\right) \leq \phi\left(z, x_{n}\right)\right\}, \\
x_{n+1}=\prod_{C_{n+1}}\left(x_{0}\right), \quad \forall n \geq 0,
\end{gathered}
$$

where $A_{n} \equiv A_{n}(\bmod N), F_{n} \equiv F_{n}(\bmod M), T_{n} \equiv T_{n}(\bmod$ $D), S_{n} \equiv S_{n}(\bmod D),\left\{r_{n}\right\} \subset[a, \infty)$ for some $a>0$ and $n \in$ $\mathbb{N}$, and $\alpha, \beta, \gamma$ are real numbers in $(0,1)$ such that $\alpha+\beta+\gamma=1$.

Then, the sequence $\left\{x_{n}\right\}_{n=0}^{\infty}$ converges strongly to $\hat{p}=$ $\Pi_{\Omega}\left(x_{0}\right)$.

5.3. Application to Hilbert Spaces. If $E=H$, a real Hilbert space, then $E$ is uniformly smooth and strictly convex real Banach space. In this case, $J=I$ and $\Pi_{C}=P_{C}$. Then, we obtain the following result.

Corollary 21. Let $C$ be a nonempty, closed and convex subset of a real Hilbert space H. Suppose that

(1) $\left\{F_{k}\right\}_{k=1}^{M}: C \times C \rightarrow \mathbb{R}$ is a finite family of bifunctions satisfying conditions (A1)-(A4), where $k=$ $1,2,3, \ldots, M$;

(2) $\left\{T_{i}\right\}_{i=1}^{D}$ and $\left\{S_{i}\right\}_{i=1}^{D}$ are finite families of nonexpansive mappings from $C$ into $C$, where $i=1,2$, $3, \ldots, D$;

(3) $\left\{A_{n}\right\}_{n=1}^{N}: C \rightarrow H$ is a finite family of continuous monotone mappings, where $n=1,2,3, \ldots, N$; 
(4) For $x \in E$, one defines the mappings $K_{r_{n}}, T_{r_{n}}: H \rightarrow C$ by

$$
\begin{aligned}
K_{r_{n}}^{\prime}(x):= & \left\{z \in C:\left\langle y-z, A_{n} z\right\rangle\right. \\
& \left.\quad+\frac{1}{r_{n}}\langle y-z, z-x\rangle \geq 0, \forall y \in C\right\} ; \\
T_{r_{n}}^{\prime}(x):= & \left\{z \in C: F_{n}(z, y)\right. \\
& \left.+\frac{1}{r_{n}}\langle y-z, z-x\rangle \geq 0, \forall y \in C\right\} .
\end{aligned}
$$

Assume that $\Omega:=\left(\bigcap_{i=1}^{D} F\left(T_{i}\right)\right) \bigcap\left(\bigcap_{i=1}^{D} F\left(S_{i}\right)\right) \bigcap\left(\bigcap_{k=1}^{M}\right.$ $\left.\operatorname{SEP}\left(F_{k}\right)\right) \bigcap\left(\bigcap_{n=1}^{N} \operatorname{VI}\left(C, A_{n}\right)\right)$ is a nonempty and bounded in $C$ and let $\left\{x_{n}\right\}$ be a sequence generated by

$$
\begin{gathered}
x_{0} \in C_{0}=C, \text { chosen arbitrary, } \\
z_{n}=K_{r_{n}}^{\prime} x_{n}, \\
u_{n}=T_{r_{n}}^{\prime} x_{n}, \\
y_{n}=\alpha x_{n}+\beta T_{n} z_{n}+\gamma S_{n} u_{n}, \\
C_{n+1}=\left\{z \in C_{n}:\left\|z-y_{n}\right\| \leq\left\|z-x_{n}\right\|\right\}, \\
x_{n+1}=P_{C_{n+1}}\left(x_{0}\right), \quad \forall n \geq 0,
\end{gathered}
$$

where $A_{n} \equiv A_{n}(\bmod N), F_{n} \equiv F_{n}(\bmod M), T_{n} \equiv T_{n}(\bmod$ $D), S_{n} \equiv S_{n}(\bmod D),\left\{r_{n}\right\} \subset[a, \infty)$ for some $a>0$ and $n \in$ $\mathbb{N}$, and $\alpha, \beta, \gamma$ are real numbers in $(0,1)$ such that $\alpha+\beta+\gamma=1$. of $\Omega$.

Then, the sequence $\left\{x_{n}\right\}_{n=0}^{\infty}$ converges strongly to an element

Remark 22. Our theorem extends and improves the corresponding results in [5-7] in the following aspect.

(a) For the mapping, we extend the mappings from nonexpansive mappings, relatively nonexpansive mappings, and weak relatively nonexpansive mappings to more general than quasi- $\phi$-nonexpansive mappings.

(b) For the common solution, we extend the common solution of a single finite family of quasi$\phi$-nonexpansive mappings to two finite families of quasi- $\phi$-nonexpansive mappings.

\section{Acknowledgments}

This work was supported by the Higher Education Research Promotion and National Research University Project of Thailand, Office of the Higher Education Commission. The first author would like to thank the Bansomdejchaopraya Rajabhat University (BSRU) for the financial support. Finally, the authors would like to thank the referees for reading this paper carefully, providing valuable suggestions and comments, and pointing out a major error in the original version of this paper.

\section{References}

[1] E. Blum and W. Oettli, "From optimization and variational inequalities to equilibrium problems," The Mathematics Student, vol. 63, no. 1-4, pp. 123-145, 1994.

[2] A. Moudafi, "A partial complement method for approximating solutions of a primal dual fixed-point problem," Optimization Letters, vol. 4, no. 3, pp. 449-456, 2010.

[3] P. M. Pardalos, T. M. Rassias, and A. A. Khan, Nonlinear Analysis and Variational Problems, vol. 35 of Springer Optimization and Its Applications, Springer, New York, NY, USA, 2010.

[4] W. R. Mann, "Mean value methods in iteration," Proceedings of the American Mathematical Society, vol. 4, pp. 506-510, 1953.

[5] W. Takahashi and K. Zembayashi, "Strong and weak convergence theorems for equilibrium problems and relatively nonexpansive mappings in Banach spaces," Nonlinear Analysis: Theory, Methods \& Applications, vol. 70, no. 1, pp. 45-57, 2009.

[6] X. Qin, Y. J. Cho, and S. M. Kang, "Convergence theorems of common elements for equilibrium problems and fixed point problems in Banach spaces," Journal of Computational and Applied Mathematics, vol. 225, no. 1, pp. 20-30, 2009.

[7] H. Zegeye and N. Shahzad, "A hybrid scheme for finite families of equilibrium, variational inequality and fixed point problems," Nonlinear Analysis: Theory, Methods \& Applications, vol. 74, no. 1, pp. 263-272, 2011.

[8] S.-y. Matsushita and W. Takahashi, "A strong convergence theorem for relatively nonexpansive mappings in a Banach space," Journal of Approximation Theory, vol. 134, no. 2, pp. 257266, 2005.

[9] S. Plubtieng and K. Ungchittrakool, "Hybrid iterative methods for convex feasibility problems and fixed point problems of relatively nonexpansive mappings in Banach spaces," Fixed Point Theory and Applications, Article ID 583082, 19 pages, 2008

[10] Y. Su, H.-k. Xu, and X. Zhang, "Strong convergence theorems for two countable families of weak relatively nonexpansive mappings and applications," Nonlinear Analysis: Theory, Methods of Applications, vol. 73, no. 12, pp. 3890-3906, 2010.

[11] I. Cioranescu, Geometry of Banach Spaces, Duality Mappings and Nonlinear Problems, vol. 62 of Mathematics and Its Applications, Kluwer Academic, Dordrecht, The Netherlands, 1990.

[12] W. Takahashi, Nonlinear Functional Analysis, Yokohama, Yokohama, Japan, 2000.

[13] Y. I. Alber, "Metric and generalized projection operators in Banach spaces: properties and applications," in Theory and Applications of Nonlinear Operators of Accretive and Monotone Type, vol. 178 of Lecture Notes in Pure and Applied Mathematics, pp. 15-50, Dekker, New York, NY, USA, 1996.

[14] S. Kamimura and W. Takahashi, "Strong convergence of a proximal-type algorithm in a Banach space," SIAM Journal on Optimization, vol. 13, no. 3, pp. 938-945, 2002.

[15] F. Kohsaka and W. Takahashi, "Existence and approximation of fixed points of firmly nonexpansive-type mappings in Banach spaces," SIAM Journal on Optimization, vol. 19, no. 2, pp. 824835, 2008.

[16] F. Kohsaka and W. Takahashi, "Strong convergence of an iterative sequence for maximal monotone operators in a Banach space," Abstract and Applied Analysis, vol. 2004, no. 3, pp. 239249, 2004.

[17] H. K. Xu, "Inequalities in Banach spaces with applications," Nonlinear Analysis: Theory, Methods \& Applications, vol. 16, no. 12, pp. 1127-1138, 1991. 


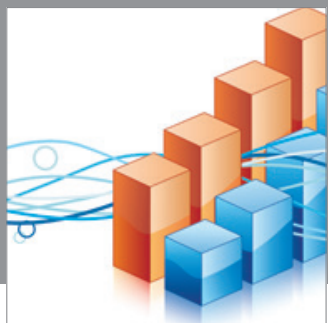

Advances in

Operations Research

mansans

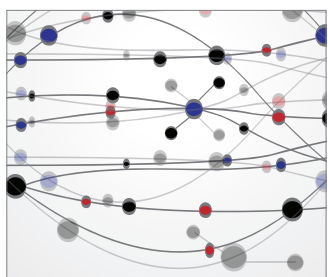

The Scientific World Journal
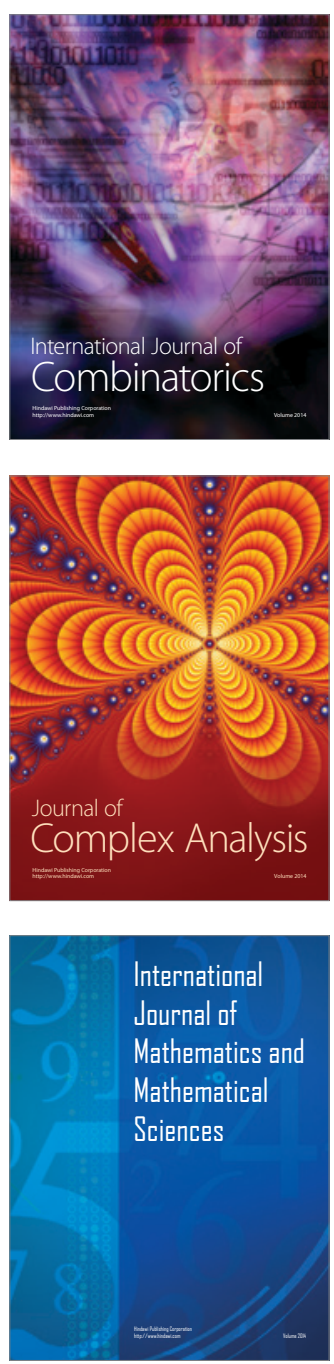
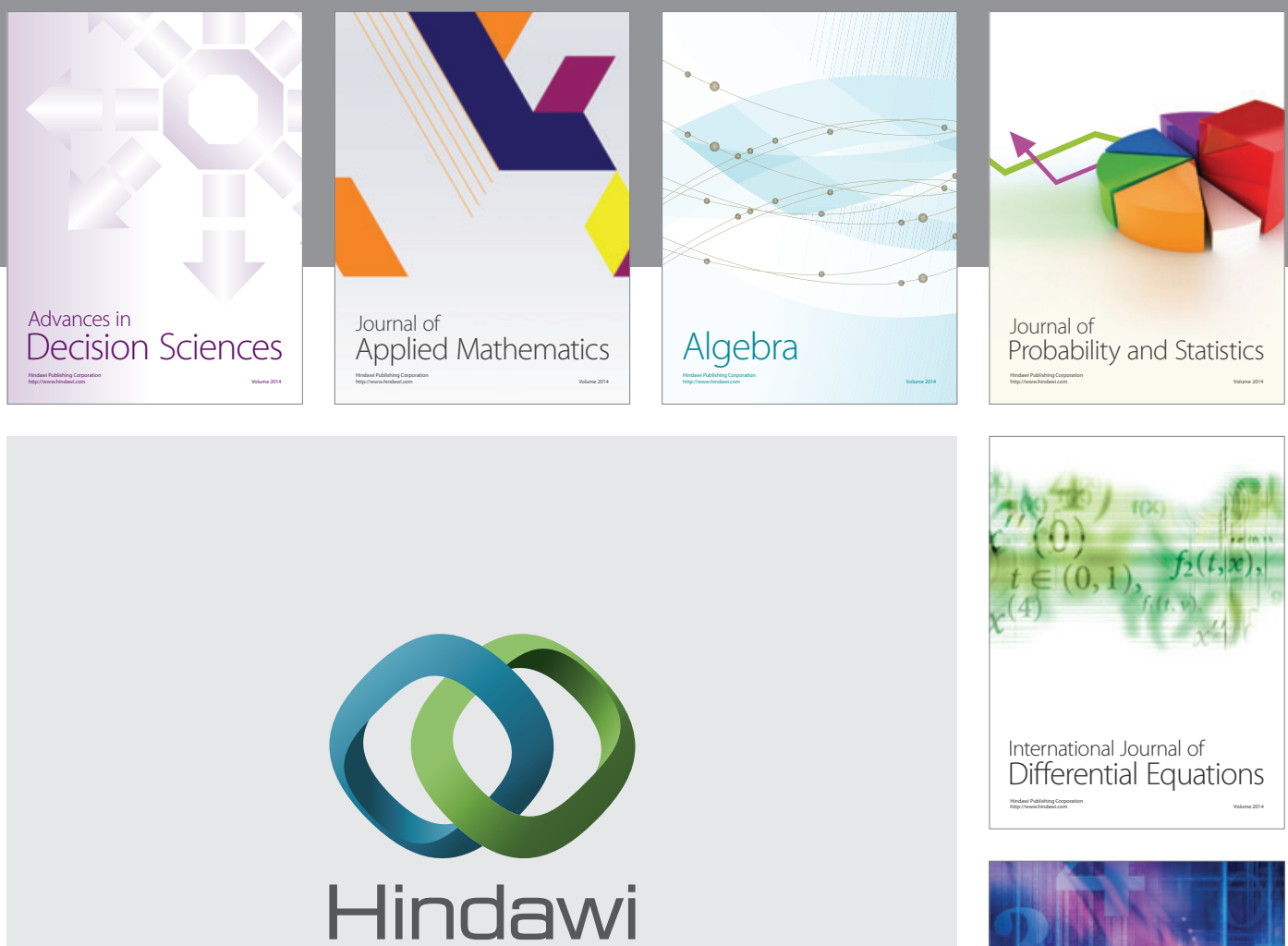

Submit your manuscripts at http://www.hindawi.com
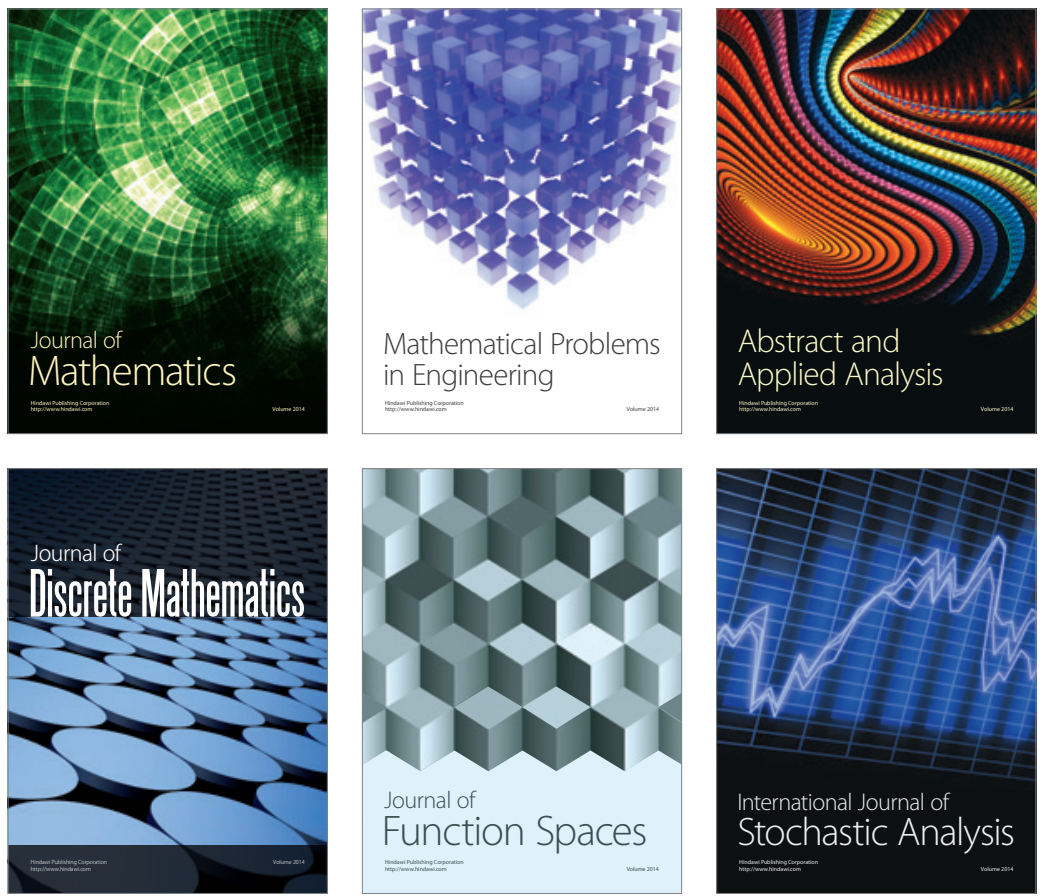

Journal of

Function Spaces

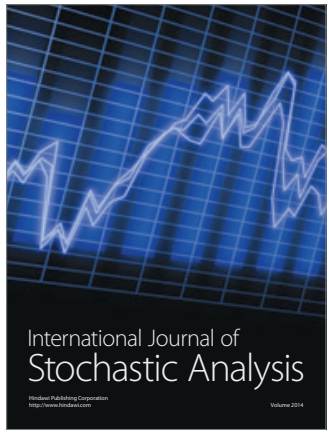

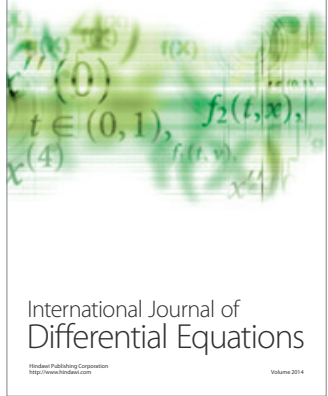
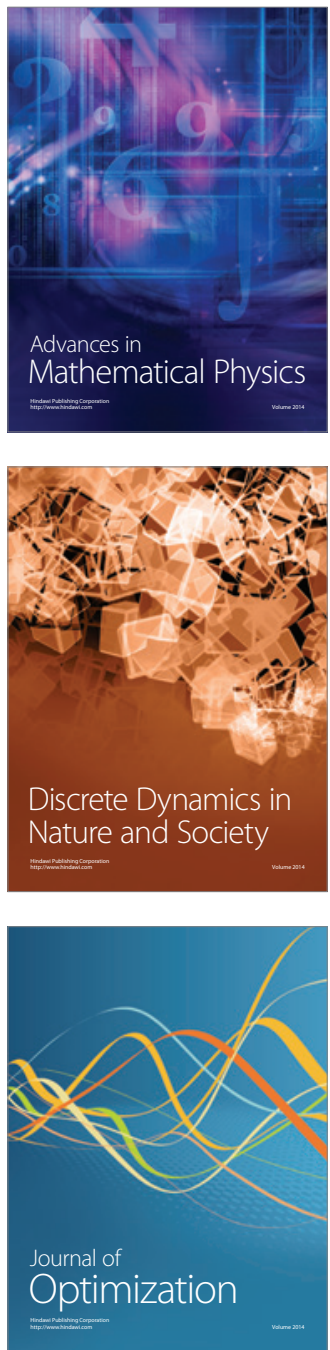